This is the final peer-reviewed accepted manuscript of:

Giuseppina Montante, Mirella Coroneo, Alessandro Paglianti, Blending of miscible liquids with different densities and viscosities in static mixers, Chemical Engineering Science, Volume 141, 2016, Pages 250-260, ISSN 0009-2509

The final published version is available online at:

https://doi.org/10.1016/i.ces.2015.11.009

Rights / License:

The terms and conditions for the reuse of this version of the manuscript are specified in the publishing policy. For all terms of use and more information see the publisher's website.

This item was downloaded from IRIS Università di Bologna (https://cris.unibo.it/)

When citing, please refer to the published version. 


\section{BLENDING OF MISCIBLE LIQUIDS WITH DIFFERENT DENSITIES AND VISCOSITIES IN STATIC MIXERS}

Giuseppina Montante ${ }^{\mathrm{a}, *}$, Mirella Coroneo $^{\mathrm{b}}$, Alessandro Paglianti $^{\mathrm{c}}$

aDepartment of Industrial Chemistry “Toso Montanari”, University of Bologna, via Terracini 28, 40131

Bologna, Italy. E-mail: giuseppina.montante@ unibo.it

${ }^{\mathrm{b}}$ former PhD student at DICMA - Department of Chemical, Mining and Environmental Engineering, University of Bologna, via Terracini 28, 40131 Bologna, Italy. E-mail: mirella.coroneo2@unibo.it.

${ }^{\mathrm{c}}$ Department of Civil, Chemical, Environmental and Materials Engineering, University of Bologna, via Terracini 28, 40131 Bologna, Italy. E-mail: alessandro.paglianti@unibo.it.

The homogenization of two liquids of different densities and viscosities in a pipeline equipped with a corrugated plate SMV static mixer is investigated by RANS-based CFD simulations. The blending effectiveness of the mixer is compared at different Richardson numbers and viscosity ratios for equal Reynolds numbers. The mixedness level is found to be a function of the Richardson number. As a result, depending on the pipeline scale, equal density differences require a different number of pipe diameters for the achievement of the same level of homogenization. The dynamic viscosity differences give rise to less marked effects, unless backmixing becomes significant. Besides the coefficient of variation of the scalar concentration, which is often adopted as a measure of the intensity of segregation in turbulent static mixers, novel definitions of the scale and of the rate of change of segregation are proposed, in order to add deeper insight into the evaluation of the mixing features.

Keywords: Static mixer; Density and viscosity differences; Scale and intensity of segregation; Miscible liquids; Blending; Computational Fluid Dynamics.

* Corresponding author (G. Montante) 


\section{Introduction}

Static mixers are often adopted as an alternative to dynamic agitators in a variety of industrial operations in chemical and process engineering. They are expected to play an increasingly important role considering the interest of industry to move towards continuous processes (Ghanem et al., 2014). The selection of the static mixing design depends mainly on the specific task and on the flow regime of the process. Similarly to mechanical agitators, general design rules for static mixers are not available (Paglianti and Montante, 2013), due to the complex fluid dynamic characteristics of each mixing device. Overall, extensive data and correlations can be found on pressure drops, at least for the most widespread designs of static mixer (Thakur et al., 2003), while the flow features and the mixing mechanisms have been investigated in a less wide number of works (Marshall and Bakker, 2004).

As for the adoption of static mixers for turbulent flows, that is the case considered in this work, advantages in industrial applications have been highlighted in a broad range of operations, from coagulation and disinfection in wastewater and water treatments (Jones et al., 2002), to emulsification (Theron and Le Sauze, 2011), heat transfer (Rakoczy et al., 2011), oxygen mass transfer in aerobic bioreactors (Ugwu et al., 2002), synthesis of pharmaceuticals (Brechtelsbauer and Ricard, 2001) and gas-liquid dispersions (Rabha et al., 2015). Amongst the different design options for turbulent flows, corrugated plate mixers are still very attractive, particularly in large diameter ducts and pipes where mixing length is limited (Etchells and Meyer, 2004). For this reason, an SMV type mixer has been considered in this investigation.

Computational Fluid Dynamics (CFD) simulations are virtually able to provide detailed information on the mixing effectiveness of static mixers and they are being increasingly adopted for the design, the optimization and the selection of operating conditions. Amongst others, successful simulations of HEV static mixers based on the solution of the Reynolds Averaged Navier-Stokes (RANS) equations have been presented by Mohand Kaci et al. (2009), who reported accurate flow field predictions either with the standard $k-\varepsilon$ turbulence models and the more advanced Reynolds stress model. Following Bałdyga et al. (1997), they suggested to evaluate the mixing efficiency of the insert based on the dissipation of turbulence kinetic energy as compared with empty pipelines. The same computational method was recently applied to the optimization of the geometrical configuration of HEV tab arrangements in heat exchangers/reactors by Habchi et al. (2010). They examined the macro-, meso- and micromixing features of the inserts based on the predictions of residence time distribution, turbulent kinetic energy and dissipation of turbulent kinetic energy, respectively. CFD based investigations on turbulent mixing using a Kenics mixer led to analyse the specific features of the transient 
behaviour of the single phase flow moving from laminar to turbulent regimes (van Wageningen et al., 2004), to propose a novel correlations for the pressure drops calculations (Kumar et al., 2008) and to predict the distribution of the local turbulent energy dissipation rate and of the droplet size distribution in turbulent liquid-liquid dispersions (Jaworski et al., 2007). Recently, Coroneo et al. (2012) have evaluated the capability of RANS simulations in predicting the main fluid dynamic characteristics in a pipeline equipped with an SMV static mixer element. The validation of the CFD model was performed by the comparison of the simulations' results with literature LDA mean velocity profiles (Karoui et al., 1997) and LIF tracer concentration data (Karoui et al., 1998).

Amongst the different aspects affecting the performances of static mixers, the consequences of density and viscosity differences upon miscible liquids blending are not widely established. To the best of our knowledge, they have never been systematically investigated in the field of turbulent in-line mixing. Knowledge is often limited to practical recommendations given by the manufacturer. Overall, the effect of the density ratio between the main and the secondary stream in turbulent liquid blending with motionless mixers is considered negligible for vertical orientation, unless the densiometric Froude number is lower than 20 (Etchells and Meyer, 2004). Comparatively, more investigations have been carried out on blending of liquids with different densities and viscosities in stirred tanks, by experiments and more recently by direct numerical simulations. Different conclusions on the impact of density differences have been achieved, depending on the initial conditions. When the two liquids are initially stably stratified, a different dependency of the mixing rate on the density difference was found at different ranges of the Richardson number (Rielly and Pandit, 1988). In addition, the increase of the Reynolds number above a critical value is suggested to achieve good mixing, depending on the viscosity ratio. For small amount of a secondary liquid, the location of the addition was found to affect the impact of the density differences, highlighting different regimes (Bouwmans et al., 1997); also, a different dependency of the density difference on the mixing time was found for different impeller types (Gogate and Pandit, 1999). Generally, as soon as the buoyancy forces become significant, the Richardson number has been found to clearly govern the fluid dynamic behaviour together with the Reynolds number (Derksen, 2011). Unlike laminar flows (Regner et al., 2008), a weak effect of the viscosity ratio upon turbulent mixing was observed (Derksen, 2012).

The turbulent blending of two miscible liquids of equal or different densities and viscosities is analyzed in this work. The model equations and the solution methods are based on previous verification and validation analysis of the single phase flow and of the tracer homogenization dynamics in the same geometry performed by Coroneo et al. (2012). 
The effect of buoyancy is assessed for variable physical properties of the two liquids and different geometrical parameters, including pipe diameter and element orientation. The effect of different viscosity ratio at constant Reynolds number is also assessed.

\section{The Model Equations}

The simulations are based on the solution of the Reynolds-Averaged conservation equations of mass, momentum and scalar concentration for incompressible, isothermal and steady-state flow of Newtonian liquids. The Reynolds stress and the Reynolds flux terms are modelled using the eddy viscosity and the eddy diffusivity hypotheses, respectively. The formulation of the equations is as follows:

$$
\begin{aligned}
& \nabla \cdot(\rho \mathbf{U})=0 \\
& \nabla \cdot(\rho \mathbf{U U})=-\nabla \mathrm{p}+\nabla \cdot\left[\left(\mu+\mu_{\mathrm{t}}\right) \nabla \mathbf{U}\right]+\rho \mathbf{g} \\
& \nabla \cdot\left(\rho \mathbf{U} \mathrm{Y}_{\mathrm{i}}\right)=\nabla \cdot\left(\rho \mathrm{D}_{\mathrm{i}, \mathrm{m}} \nabla \mathrm{Y}_{\mathrm{i}}+\frac{\mu_{\mathrm{t}}}{\sigma_{\mathrm{t}}} \nabla \mathrm{Y}_{\mathrm{i}}\right) \\
& \rho=\frac{1}{\sum_{\mathrm{i}} \frac{\mathrm{Y}_{\mathrm{i}}}{\rho_{\mathrm{i}}}} ; \quad \mu=\sum_{\mathrm{i}} \mathrm{Y}_{\mathrm{i}} \mu_{\mathrm{i}}
\end{aligned}
$$

Where $\mathbf{U}$ is the mean velocity vector, $\rho_{\mathrm{i}}$ is the density of the fluid species $i, \rho$ the volume averaged density of the fluids, $\mathbf{g}$ is the gravity acceleration, $\mu_{\mathrm{i}}$ is the viscosity of the fluid species $\mathrm{i}, \mu$ is the mass averaged viscosity of the fluids, $\mathrm{p}$ is the pressure, $\mathrm{Y}_{\mathrm{i}}$ is the mass fraction of the liquid species i, $\mu_{t}$ is the turbulent viscosity, $\sigma_{t}$ is the turbulent Schmidt number and $D_{m}$ is the molecular diffusivity.

The molecular diffusivity is fixed to the value of $10^{-9} \mathrm{~m}^{2} / \mathrm{s}$ regardless of the fluid considered. Its contribution is expected to be negligible, while the overall scalar dispersion is dominated by the turbulent diffusivity. It is defined as the ratio between the turbulent viscosity, which results from the turbulence closure equations, and the turbulent Schmidt number. This last parameter is fixed at 0.7 , as is commonly suggested (Hartmann et al., 2006). The adequacy of this value is confirmed by the preliminary validation tests of Coroneo et al. (2012) and by the experimental determination of Feng et al. (2007; 2010). 
Based on previous results (Coroneo et al., 2012), the RANS equations are closed with the following standard $k-\varepsilon$ model equations:

$$
\begin{aligned}
& \nabla\left(\rho U \mathrm{k}-\left(\mu+\frac{\mu_{\mathrm{t}}}{\sigma_{\mathrm{k}}}\right) \nabla \mathrm{k}\right)=\mathrm{G}_{\mathrm{k}}+\mathrm{G}_{\mathrm{b}}-\rho \varepsilon \\
& \nabla\left(\rho U \varepsilon-\left(\mu+\frac{\mu_{\mathrm{t}}}{\sigma_{\varepsilon}}\right) \nabla \varepsilon\right)=\left(\mathrm{C}_{1} \mathrm{G}_{\mathrm{k}}+\mathrm{C}_{1} \mathrm{C}_{3} \mathrm{G}_{\mathrm{b}}-\mathrm{C}_{2} \rho_{\mathrm{c}} \varepsilon\right) \frac{\varepsilon}{\mathrm{k}} \\
& \mu_{\mathrm{t}}=\mathrm{C}_{\mu} \frac{\mathrm{k}^{2}}{\varepsilon} \\
& \mathrm{C}_{3}=\tanh \left|\frac{\mathrm{u}_{\mathrm{x}}}{\mid \mathrm{u}_{\mathrm{z}}}\right|
\end{aligned}
$$

Where $\mathrm{k}$ is the turbulent kinetic energy, $\varepsilon$ is the dissipation of turbulent kinetic energy, $\mathrm{C}_{\mu}, \mathrm{C}_{1}$, $\mathrm{C}_{2}, \sigma_{\mathrm{k}}, \sigma_{\varepsilon}$, are the standard $\mathrm{k}-\varepsilon$ model constants, $\mathrm{G}_{\mathrm{k}}$ is the k production due to the mean velocity gradient, $\mathrm{G}_{\mathrm{b}}$ is the k production due to buoyancy, $\mathrm{u}_{\mathrm{x}}$ is the velocity component parallel to $\mathrm{g}, \mathrm{u}_{\mathrm{z}}$ is the velocity component perpendicular to $g$.

$\mathrm{G}_{\mathrm{b}}$ is nil when the two liquids have the same density, while in case of different densities, it is calculated as follows (Zhao et al., 2010):

$$
\mathrm{G}_{\mathrm{b}}=-\mathrm{g} \frac{\mu_{\mathrm{t}}}{\rho \sigma_{\mathrm{t}}} \nabla \rho
$$

The viscosity-affected regions between the walls and the fully-turbulent zones are bridged by the standard wall functions (Launder and Spalding, 1974).

\section{The Computational Domain and the Numerical Details}

Two horizontal pipelines are considered: one is coincident with that already investigated by Coroneo et al. (2012), the other has doubled dimensions and identical geometrical features. Each pipeline is equipped with one SMV element, which consists of corrugated plates forming open intersecting channels. The intersecting plates and channels encourage rapid mixing in combination with plug flow progression. The geometry of the two computational domains is depicted in Fig. 1. 
The main pipe diameter $\mathrm{D}$ is equal to either $50 \mathrm{~mm}$ or $100 \mathrm{~mm}$ and the length is equal to $10 \times \mathrm{D}$. The secondary flow enters the main pipe by a coaxial tube of internal diameter, $\mathrm{D}_{\mathrm{S}}$, equal to $\mathrm{D} / 5$. The static mixer element has standard length $(\mathrm{L}=\mathrm{D})$ and consists of 5 corrugated plates, forming channels inclined of $45^{\circ}$ with respect to the pipeline main axis. The mixer inlet section is positioned at $3 \mathrm{D}$ from the main tube inlet section and at $0.4 \times \mathrm{D}$ from the secondary tube exit surface. Further details on the geometrical configuration of the mixer can be found in Karoui et al.(1997).

The domain is discretized through an unstructured grid consisting of about $5 \times 10^{6}$ cells for the larger domain and $4 \times 10^{6}$ for the smaller. The grid independency of the results is ensured by previous verification on the smaller scale performed for single phase flows and for the blending of a liquid tracer with the main water stream (Coroneo et al., 2012). The grid effect was checked for the mean velocity field, the turbulent variables and the degree of homogenization. The requirements for achieving strict grid independency were different for the mean velocities and for the turbulent variables. As a result, the species concentration distribution is more sensitive to the mesh refinement with respect to the mean flow field, due to the turbulent viscosity affected term in the scalar transport equation (Eqn. 3).

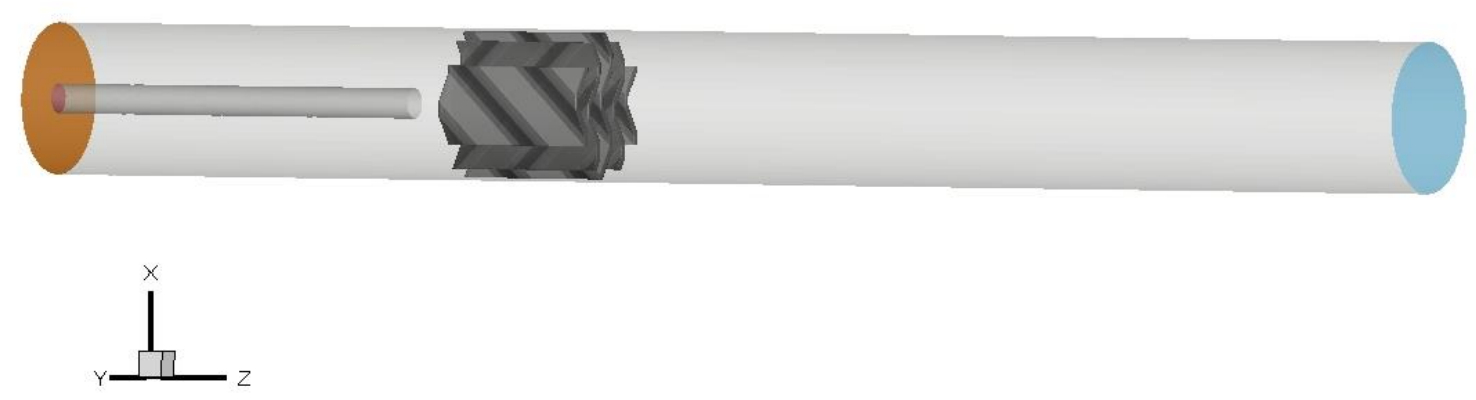

Fig.1. Geometry of the computational domain.

The model equations are numerically solved by adopting the finite volume CFD code FLUENT 6.3. The conservation equations are integrated in space using a second order upwind discretization scheme for the convective terms. The SIMPLEC algorithm is used to couple pressure and velocity. At the walls of the static mixer insert and of the pipelines no-slip conditions are imposed. At the two fluid flow entrances, velocity inlet boundary conditions are selected. At the domain outlet boundary a pressure of $1.01 \times 10^{5} \mathrm{~Pa}$ is set.

The solution convergence is checked by monitoring the residuals of all the variables, the mass balance and the concentration of the scalars at the outlet section. At the end of the calculations, most of the variables residuals are dropped to the order of $10^{-6}$. 
The model equations are written with respect to a fixed Cartesian coordinate system: $\mathrm{x}, \mathrm{y}, \mathrm{z}$. The origin is placed on the centre of the downstream surface of the SMV element. The pipeline axis is placed along the $\mathrm{z}$ direction, while the gravity vector acts along the negative $\mathrm{x}$ direction, unless differently specified.

\section{The flow conditions}

Various flow rates and physical properties of the two liquid streams are considered, thus changing the density and viscosity differences between the two liquids, at equal Reynolds numbers.

In the following, the pipelines of $50 \mathrm{~mm}$ and $100 \mathrm{~mm}$ will be named D50 and D100 respectively, while the subscript $\mathrm{M}$ and $\mathrm{S}$ will be adopted for the variables relevant to the main and the secondary flow, respectively.

The investigated conditions are summarized in Table 1.

\begin{tabular}{l|ccccccc} 
Case & $\rho_{\mathrm{M}}\left[\mathrm{kg} / \mathrm{m}^{3}\right]$ & $\rho_{\mathrm{S}}\left[\mathrm{kg} / \mathrm{m}^{3}\right]$ & $\mathrm{Re}_{\mathrm{M}} \times 10^{4}$ & $\mathrm{Re}_{\mathrm{S}} \times 10^{4}$ & $\mathrm{Ri}$ & $\mathrm{Q}_{\mathrm{M}} / \mathrm{Q}$ & $\mu_{\mathrm{M}} / \mu_{\mathrm{S}}$ \\
\hline \hline D50_A & 993 & 993 & 3.02 & 28.9 & 0.00 & 0.34 & 1.00 \\
\hline D50_B & 993 & 1243 & 3.02 & 36.2 & 0.03 & 0.34 & 1.00 \\
\hline D50_C & 993 & 1243 & 1.51 & 18.1 & 0.13 & 0.34 & 1.00 \\
\hline D50_D & 993 & 1243 & 3.02 & 9.05 & 0.13 & 0.68 & 1.00 \\
\hline D50_F & 800 & 800 & 2.43 & 0.91 & 0.00 & 0.93 & 1.00 \\
\hline D50_F' & 800 & 1243 & 2.43 & 0.91 & 0.61 & 0.95 & 1.00 \\
\hline D50_F', & 1243 & 800 & 2.43 & 0.91 & -0.90 & 0.90 & 1.00 \\
\hline D100_F & 800 & 800 & 2.43 & 0.91 & 0.00 & 0.93 & 1.00 \\
\hline D100_F' & 800 & 1243 & 2.43 & 0.91 & 5.30 & 0.95 & 1.00 \\
\hline D100_F', & 1243 & 800 & 2.43 & 0.91 & -7.76 & 0.90 & 1.00 \\
\hline D100_G & 800 & 1243 & 2.43 & 0.91 & 0.16 & 0.99 & 6.00 \\
\hline D100_G' & 800 & 1243 & 2.43 & 0.91 & 0.03 & 1.00 & 15.00 \\
\hline D100_H & 800 & 1243 & 2.43 & 0.91 & 3.21 & 0.78 & 0.17 \\
\hline D100_H' & 800 & 1243 & 2.43 & 0.91 & 1.64 & 0.58 & 0.07 \\
\hline
\end{tabular}

Table 1: Physical properties of the main and the secondary flows and relevant dimensionless numbers.

The Reynolds number is calculated with reference to the inlet sections of the main ( $\left.\mathrm{Re}_{\mathrm{M}}\right)$ and the secondary flows $\left(\operatorname{Re}_{S}\right)$. The Richardson number, $\mathrm{Ri}$, which is a measure of the ratio between buoyancy and inertial forces, is calculated as follows: 
$\mathrm{Ri}=\frac{\left(\rho_{\mathrm{S}}-\rho_{\mathrm{M}}\right) \mathrm{gD}}{\rho \mathrm{v}_{\mathrm{av}}^{2}}$

where $\mathrm{V}_{\mathrm{av}}$ is the average superficial velocity, based on the volumetric flow rate of the two streams. It is worth observing that, with two pipe sizes selected, the investigated range of Richardson numbers can be widened at equal Reynolds numbers, while maintaining physically sound values of liquid densities and flow rates in the pipes.

The effect of the Reynolds number is first investigated with reference to the operating condition examined by Coroneo et al. (2012), that is the blending of a main stream of water with a secondary stream of Rhodamine solution of equal density (D50_A). In three additional cases (D50_B, D50_C, D50_D), the density of the main flow is kept constant, while a solution of sodium hypochlorite at $15 \mathrm{vol} . \%$ in water is considered as the secondary flow, whose density is 1.25 times bigger than the water density. In the D50_B case, the same flow rates of case A are used, therefore a slight variation of $\mathrm{Re}_{\mathrm{s}}$ is obtained. Instead, for D50_C, the flow rates of both the streams and consequently the Reynolds numbers are halved, thus maintaining the same flow rate ratio. Finally in the D50_D case, the flow rate of the smaller pipe stream is reduced to one fourth with respect to the reference case D50_A.

The effect of buoyancy is considered at equal Reynolds numbers for both D50 and D100 for the cases named F, F' and F', where the viscosity of both the liquids is assumed equal to $1 \mathrm{mPa} \cdot \mathrm{s}$. In addition, for buoyancy affected cases (D100_F' and D100_F''), the insert is rotated of 90 (case $\mathrm{G}$ ) and of $180^{\circ}$ (case $\mathrm{H}$ ) respect to the axis $\mathrm{z}$ of the pipeline, while maintaining the horizontal position of the pipe.

The viscosity difference is considered in the cases G, G' (dynamic viscosity of the main flow, $\mu_{\mathrm{M}}$, equal to 6 and $15 \mathrm{mPa} \cdot \mathrm{s}$, respectively) and $\mathrm{H}, \mathrm{H}^{\prime}$ (dynamic viscosity of the secondary flow, $\mu_{\mathrm{s}}$, equal to 6 and $15 \mathrm{mPa} \cdot \mathrm{s}$, respectively).

\subsection{Intensity, scale and exposure of segregation}

The coefficient of variation, $\mathrm{CoV}$, is calculated at different pipe cross sections with the usual definition:

$$
\mathrm{CoV}=\sqrt{\frac{\sum_{\mathrm{j}=1}^{\mathrm{N}}\left(\Phi_{\mathrm{S}, \mathrm{j}}-\Phi_{\mathrm{S}, \text { mean }}\right)^{2}}{\mathrm{~N}-1}} \frac{1}{\Phi_{\text {mean }}}
$$


Where $\Phi_{\mathrm{S}, \mathrm{j}}$ is the local volume fraction of the secondary liquid at the $\mathrm{j}$-th computational cell, $\Phi_{\mathrm{S} \text {,mean }}$ is the mean volume fraction of the secondary liquid on the cross section and $\mathrm{N}$ is the number of cells on the cross section. Under the investigated conditions, the CoV defined by Eqn. (11), the $\mathrm{CoV}$ based on the mass fraction and the $\mathrm{CoV}$ based on the mass fraction multiplied for the axial velocity are practically coincident.

The standard CoV evaluation provides the intensity of segregation. The adoption of two additional parameters for the evaluation of turbulent blending processes is proposed in this work, following the general mixing concepts firstly introduced by Danckwerts (1952) and recently further developed by Kukukova et al. (2009). The effective application of this idea to the case of laminar in-line mixing and to the case of laminar and transitional flows in impinging jets mixers has been recently presented by Alberini et al. (2014a,b) and by Fonte et al. (2015), respectively. The two additional dimensions are the scale of segregation, that focuses on the distribution of length scales or the arrangement of the fluid volumes in the mixing field, and the rate of change of segregation, that addresses the effectiveness of the equipment in the reduction of segregation. Due to the wide variation of the different mixing processes of industrial interest, an appropriate definition is required, depending on the involved physical phenomena. The case of turbulent mixing of miscible liquids has not been specifically considered so far.

Since the striation boundaries are quickly smeared in turbulent flows (Kukukova et al., 2011), a different definition of the scale of segregation with respect to the case of laminar mixing is proposed here. It is based on the local identification of the distribution of the fully mixed zones, whose resolution corresponds to the computational cell size. This definition is close to the areal distribution concept of Alberini et al. (2014b), with suitable modifications for the case of turbulent mixing.

The first step is the definition of a threshold for complete mixedness, that is usually based on the value of the local concentration of the secondary species with respect to the complete homogenization value. The degree of homogeneity of $X=95 \%$ has been chosen, that is the computational cell is considered completely mixed if the concentration value deviates of $\pm 5 \%$ from the mean. Stricter limits for the degree of homogeneity can be selected when required, such as for pharmaceutical productions processes (Brown et al., 2004) or paints. Based on this threshold, each cell of the computational domain can be classified either well mixed or not sufficiently mixed.

The iso-surface of the interface between the two zones based on $X=95 \%$ is shown in Fig. 2, for case D100_F; as can be observed, the appearance of well mixed fluid zones starts far 
downstream of the insert. The well mixed area on the outlet section, also shown in Fig. 2, highlights that only a small portion of the pipe cross section is well mixed at the exit.

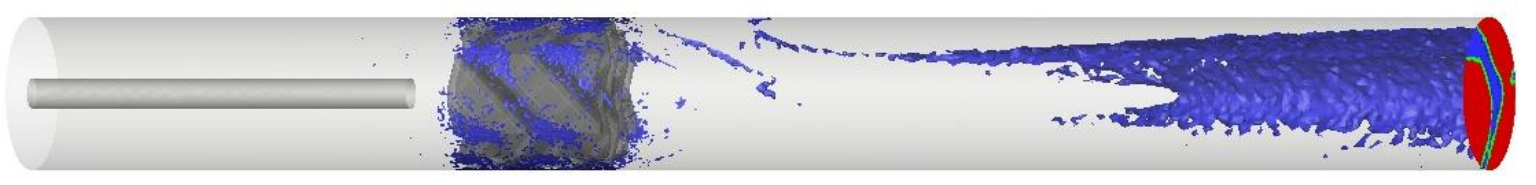

Fig. 2. Iso-surface of the interface between the zones (violet). On the outlet section: well mixed (blue) and poorly mixed (red) cells.

In order to move from a visual representation to a quantitative estimation method of the scale of segregation, the distribution of the well mixed zones is considered on the pipe cross sections along the axis (Fig. 3a) and the boundaries between the well mixed and poorly mixed zones can be identified (Fig. 3b). As a result, the total well mixed area, $A_{M}$, and the total length of the boundary between the two zones, $\mathrm{L}_{\mathrm{M}}$, can be calculated on each cross section of the pipe.

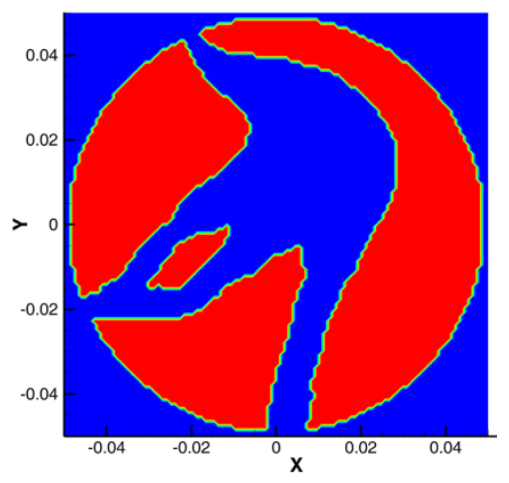

(a)

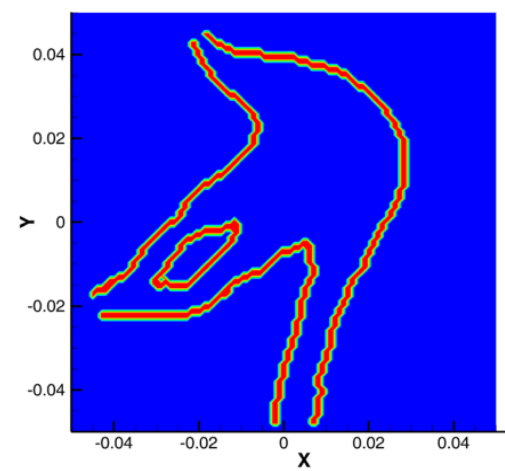

(b)

Fig. 3. (a) Distribution of well mixed (blue) and poorly mixed (red) cells; (b) Boundary between the two zones.

Finally, the scale of segregation on each cross section can be estimated as the equivalent diameter, $d_{\text {eq }}$, that is the ratio between $4 \times A_{M}$ and $L_{M}$.

The third dimension of segregation proposed by Kukukova et al. (2009), that is related to both the intensity and the scale of segregation, is the rate of change of segregation. It can be estimated through the standard definition of mass transfer rate, that depends on a mass transfer coefficient, giving the strength of interaction between the two liquid species, the concentration gradient and the interfacial area. Based on the definition of the equivalent diameter, its variation along the 
pipe axial coordinate $\mathrm{z}, \Delta \mathrm{d}_{\mathrm{eq}} / \Delta \mathrm{z}$, can be considered as a measure of the probability of the two liquid species to interact, that is proportional to the exposure of the process.

\section{Results and discussion}

\subsection{The effect of the Reynolds number}

The effect of the Reynolds number is assessed on the smaller tube preliminary to the investigation on the density and viscosity differences.

The main features of the homogenization of the two liquids for the first four cases listed in Table 1 can be evaluated by a comparison of the local volumetric fraction of the secondary flow in the vertical plane passing through the tube axis shown in Fig. 4. As can be observed, going from equal (D50_A) to different density of the two streams (D50_B) at equal $\mathrm{Re}_{\mathrm{M}}$, apart from a slightly different degree of back-mixing upstream of the SMV element, negligible differences are obtained. The volume fraction distribution does not undergo appreciable variations halving both the flow rates and consequently the two Reynolds numbers (D50_C). On the other hand a significantly different result is obtained for a lower flow rate in the smaller tube (D50_D). Downstream of the SMV element the different values of the volume fraction with respect to the previous cases are an obvious consequence of the different flow rate of the secondary stream, while upstream of the insert, the reason is the different extend of back-mixing.

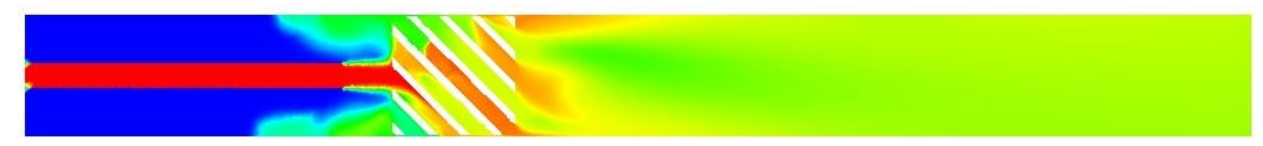

(D50_A, Ri=0.0; $\operatorname{Re}_{\mathrm{M}}=3.02 \times 10^{4} ; \mathrm{Re}_{\mathrm{S}}=28.90 \times 10^{4}$ )

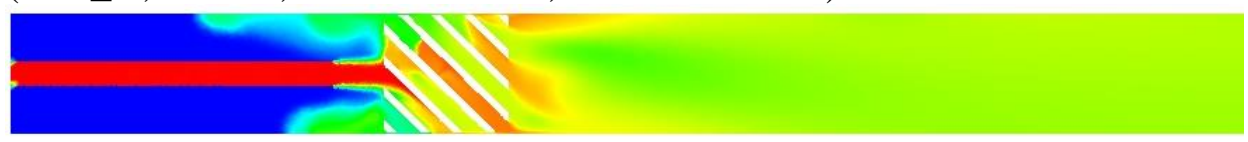

(D50_B, Ri=0.03; Re $\mathrm{M}_{\mathrm{M}}=3.02 \times 10^{4} ; \mathrm{Re}_{\mathrm{S}}=36.20 \times 10^{4}$ )
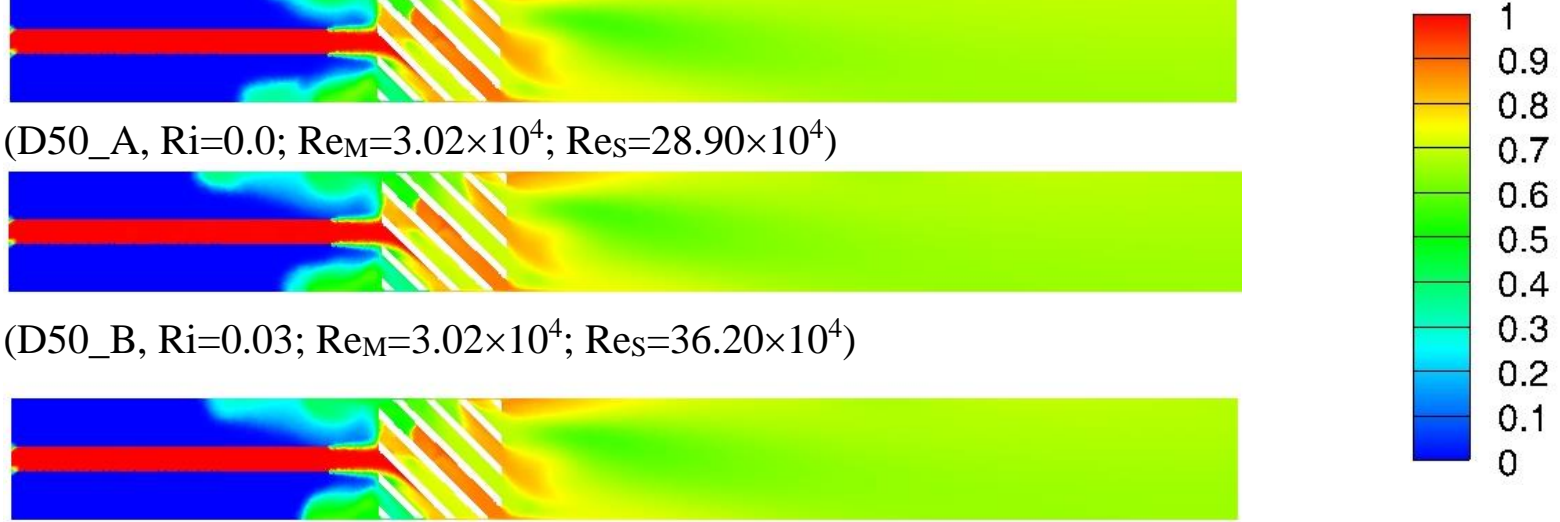

0.1

(D50_C, Ri=0.13; $\operatorname{Re}_{M}=1.51 \times 10^{4} ; \mathrm{Re}_{S}=18.10 \times 10^{4}$ )

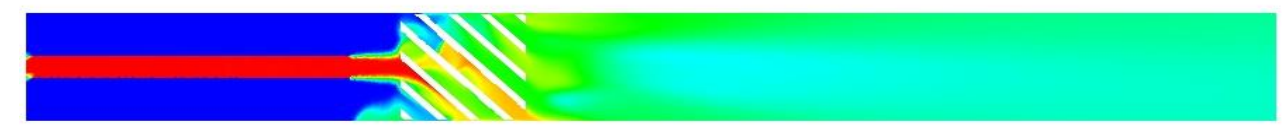

(D50_D, Ri=0.13; $\mathrm{Re}_{\mathrm{M}}=3.02 \times 10^{4} ; \mathrm{Re}_{\mathrm{S}}=9.05 \times 10^{4}$ )

Fig.4. Volume fraction of the secondary flow on a diametrical vertical plane of the pipe. 
The comparison of the CoV profiles shown in Fig. 5 highlights that in the four cases considered, the intensity of segregation is affected significantly only by the ratio of the two flow rates. As far as it is maintained constant, as for D50_B and D50_C $\left(\operatorname{Re}_{S} / \operatorname{Re}_{M}=12\right)$, the same homogeneity level is obtained, while important deviations are observed for $D 50 \_D\left(\operatorname{Re}_{S} / \operatorname{Re}_{M}=3\right)$. A negligible effect is instead observed either for density differences and for Reynolds number variations, at least as far as the fully turbulent conditions are maintained.

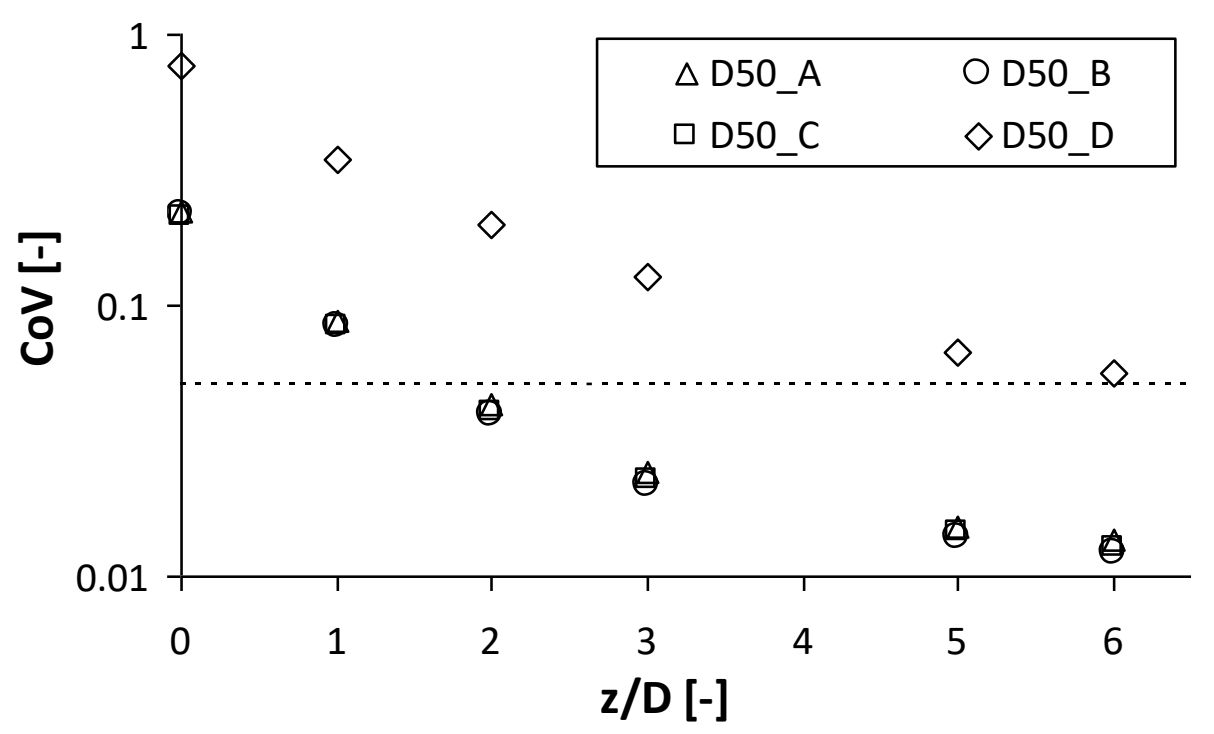

Fig.5. Evolution of the CoV downstream of the mixer for different operating conditions in D50 (D50_A: $\operatorname{Re}_{S} / \operatorname{Re}_{M}=9.6$; D50_B: $\operatorname{Re}_{S} / \operatorname{Re}_{M}=12 ; \mathrm{D} 50 \_C: \operatorname{Re}_{S} / \operatorname{Re}_{M}=12 ; \mathrm{D} 50 \_D: \operatorname{Re}_{S} / \operatorname{Re}_{M}=3$ ).

\subsection{The effect of the Richardson number}

The mass fraction of the secondary liquid normalized by the value corresponding to complete mixedness at five diameters from the downstream surface of the static mixer is shown in Fig. 6, for different Richardson numbers. It clearly demonstrates that the liquid blending is importantly affected by the Richardson number, while the density difference by itself does not provide any indication on the buoyancy effect.

In D50 identical distributions of the secondary flow are obtained for the same (D50_F) or higher (D50_F') density than that of the main flow. The map exhibits similar overall distribution at different angular location in the case of the lighter secondary stream (D50_F'). 
The same liquid distribution is obtained for D50 and D100 in case of equal density, as expected since the selected set of the four non-dimensionalized parameters $\left(\operatorname{Re} e_{M}, \operatorname{Re} S\right.$, Ri and $\left.\mu_{M} / \mu_{S}\right)$ have identical values. Instead, the same density difference gives rise in D100 to much higher Richardson numbers than those relevant to D50 and correspondingly to significantly different liquids distributions (D100_F' and D100_F'').

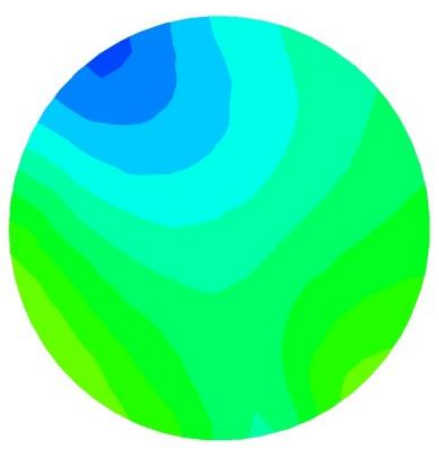

(D50_F; Ri=0.0)

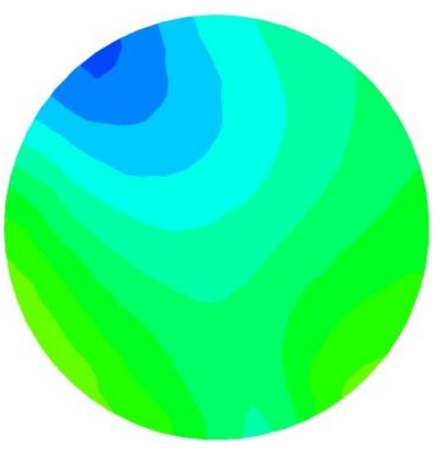

(D100_F; Ri=0.0)

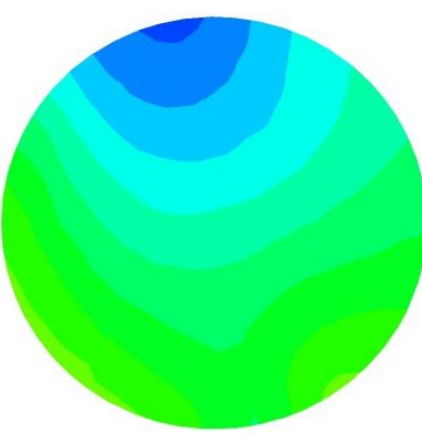

(D50_F'; Ri=0.61)

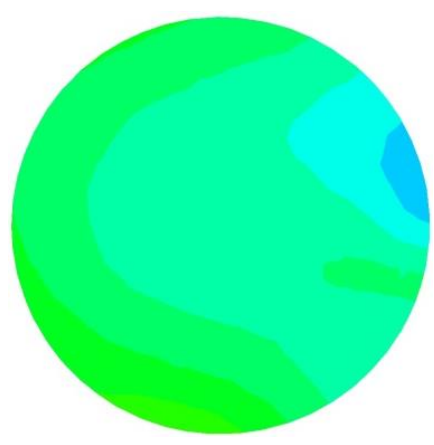

(D100_F'; Ri=5.30)

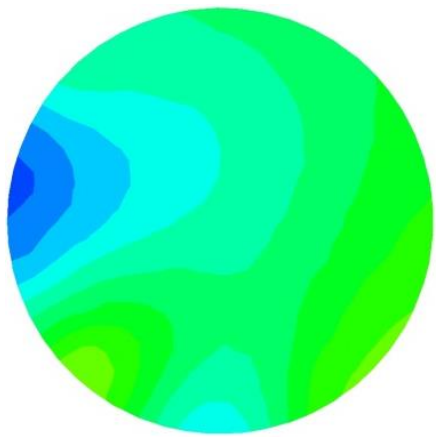

(D50_F'; Ri=-0.90)

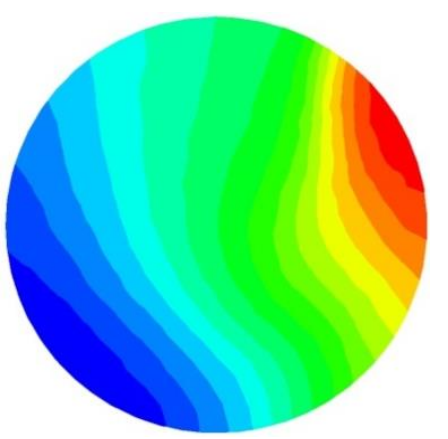

(D100_F', Ri=-7.76)

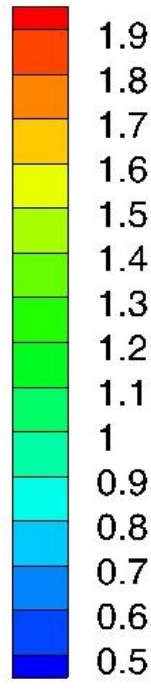

1.8

1.7

1.6

1.4

1.3

1.2

1.1

0.9

0.8

0.7

0.6

0.5

Fig. 6. Normalized mass fraction of the secondary liquid at $\mathrm{z} / \mathrm{D}=5$.

Overall, the liquid distribution is significantly affected by the density difference as soon as the Richardson number moves far enough from zero. A quantitative confirmation of this observation is provided in Fig. 7, where the CoV profiles are shown for the six cases reported in Fig. 6. The four profiles relevant to Richardson numbers equal or close to zero are coincident, while significant deviations are obtained in the other two cases. As a result, positive or detrimental effects of the density difference upon liquid blending are observed for the bigger tube only, being the blending improved in the case of denser secondary stream and worsened if the liquid density difference is reversed. It is worth observing that for the investigated cases, the criterion given by some manufacturers on the buoyancy effect for turbulent flows (Streiff et al., 1999; Etchells and Meyer, 2004), i.e. the suggestion of considering the density difference just for densiometric Froude numbers (that is the root square of the Richardson number reciprocal) lower than 20 , is not sufficient. 
The comparison of the different cases clearly demonstrates that the Richardson number can be confidently adopted as the scaling parameter for the buoyancy effect upon miscible liquids blending.

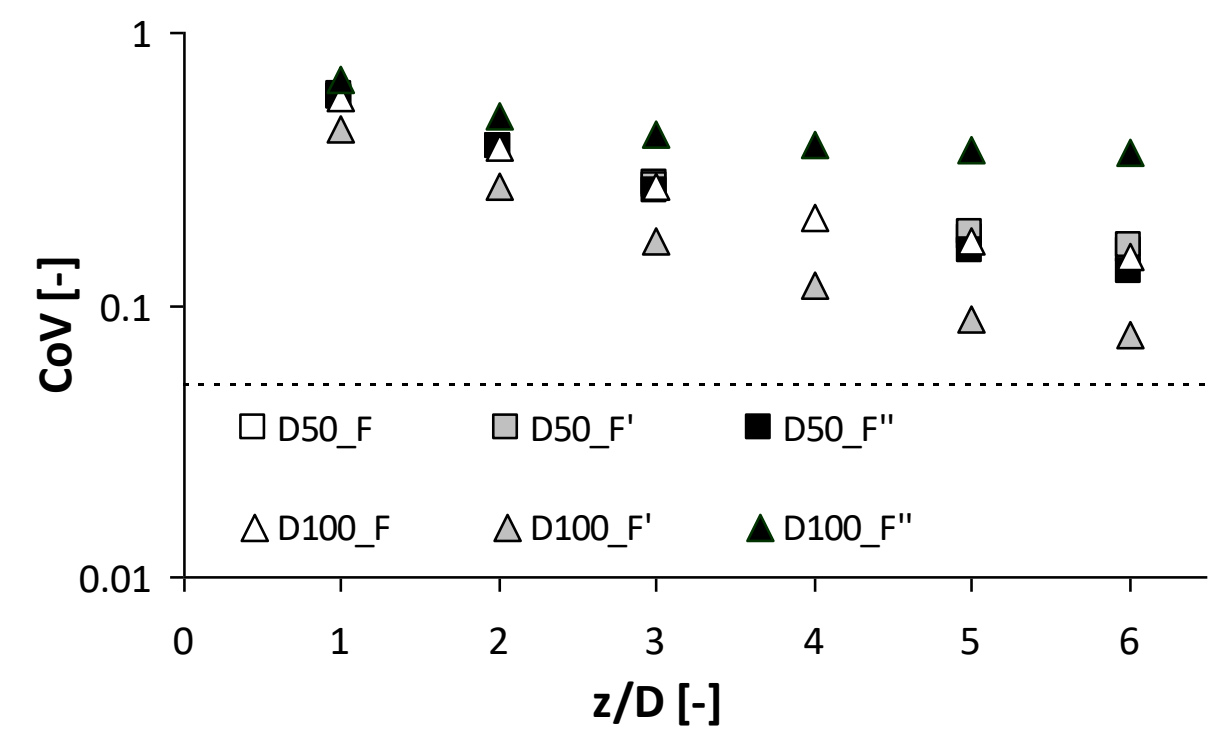

Fig. 7. Evolution of the $\mathrm{CoV}$ downstream of the mixer for different operating conditions in the two pipes (D50 and D100). (D50_F: Ri=0.0; D50_F': Ri=0.61; D50_F'? Ri=-0.90; D100_F: $\mathrm{Ri}=0.0$; D50_F': Ri=5.30; D50_F'?: Ri=-7.76).

Besides, significant modifications of the flow field and of the vorticity characteristics are observed at equal Reynolds numbers depending on the Richardson number. As an example, the velocity vectors coloured by the helicity, that is defined as the vector dot product between vorticity and velocity, are shown in Fig. 8 at z/D=0.5 of D100. 


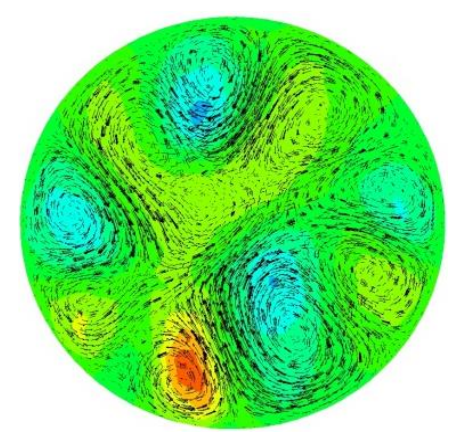

(D100_F; Ri=0.0)

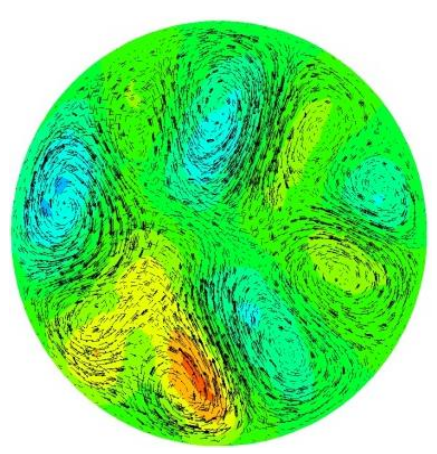

(D100_F'; Ri=5.30)

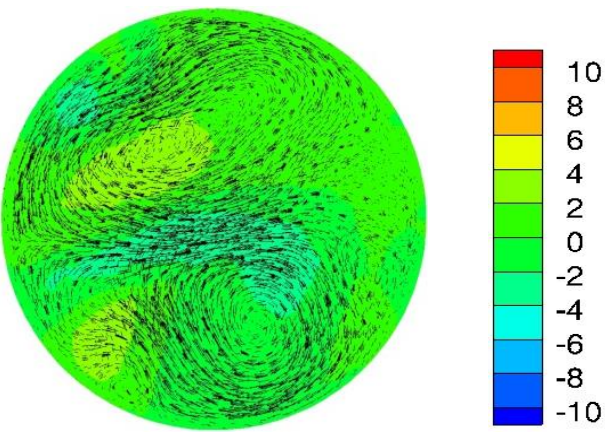

(D100_F"; Ri=-7.76)

Fig. 8. Flow structures (vectors) and helicity (colour map in $\mathrm{m} / \mathrm{s}^{2}$ ) for the cases D100 downstream of the mixer.

The helicity highlights the presence of different longitudinal counter-rotating vortices (positive and negative values for clockwise and anti-clockwise rotation, respectively), whose structure is different depending on the Richardson number. Major differences are obtained for the case of lighter secondary stream (D100_F'"), as also shown in Fig. 9, where the isosurfaces of helicity for the cases D100_F' and D100_F', are shown on the whole volume. The better mixing obtained in case F' than in F', is consistent with the more pronounced vortical structure of the flow downstream of the insert.

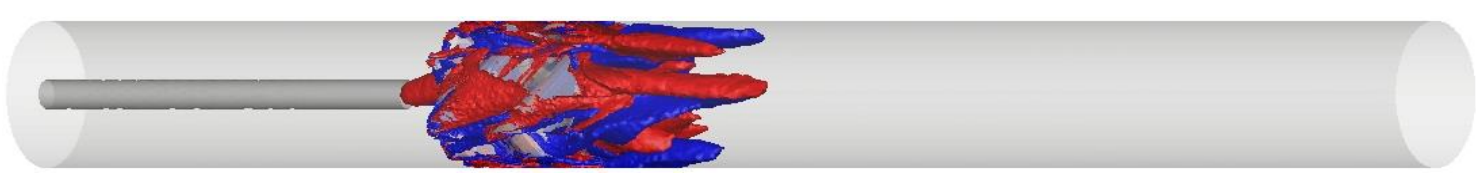

D100_F'

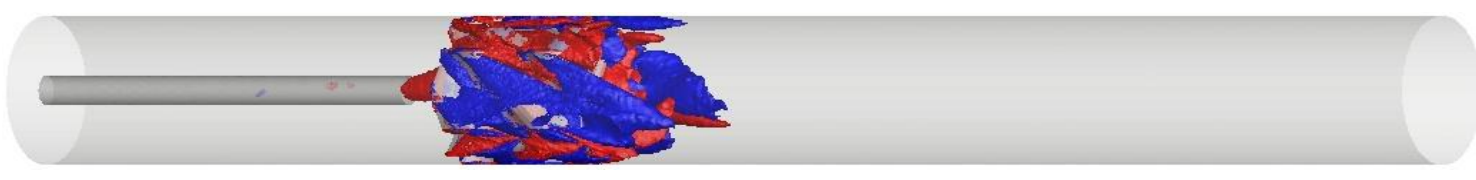

D100_F"

Fig. 9. Longitudinal vortices shown by the isosurfaces of helicity (blue: $-5 \mathrm{~m} / \mathrm{s}^{2}$, red: $5 \mathrm{~m} / \mathrm{s}^{2}$ ).

\subsection{The effect of the element orientation}

For the cases D100_F' and D100_F', two additional element orientations are considered, in order to assess whether casual or specific positioning of the insert inside the horizontal pipe may affect the mixer efficiency. The CoV profiles obtained with the element rotated of $90^{\circ}$ and of 
$180^{\circ}$ with respect to the standard orientation lead to different conclusions, depending on the density of the two streams, as can be observed in Fig. 10.

As for the case of denser secondary flow (Fig. 10a), the importance of orientation is apparent, while for the lighter secondary flow (Fig. 10b) the element orientation does not affect the intensity of segregation. In the former case (D100_F'), a worsening of homogenization at equal tube length is obtained with both the orientations, although minor differences can be appreciated with the $180^{\circ}$ rotated element with respect to the $90^{\circ}$ rotation. This result may be partially explained considering the modified initial distribution of the secondary flow inside the mixer, which can be clearly appreciated in Fig. 11. As can be observed, with the $90^{\circ}$ arrangement just two channels of the mixer are filled with the secondary flow, while with the standard orientation the secondary liquid jet reaches the tube walls and with a $180^{\circ}$ rotation, the flow is distributed in a wider portion of the mixer. For the case of denser main flow (D100_F'), although the entrance of the secondary flow in the insert varies as in the cases D100_F', the concentration distribution downstream of the mixer exhibits negligible differences (Fig. 10b).

Therefore, additional physical insight is required by a deeper analysis of the local value of the mean flow and of the turbulent variables associated with the geometrical variations and buoyancy, which in turn affect the exchange rate between the two streams. These aspects will be better addressed in the following-by the analysis of the three dimensions of segregation.

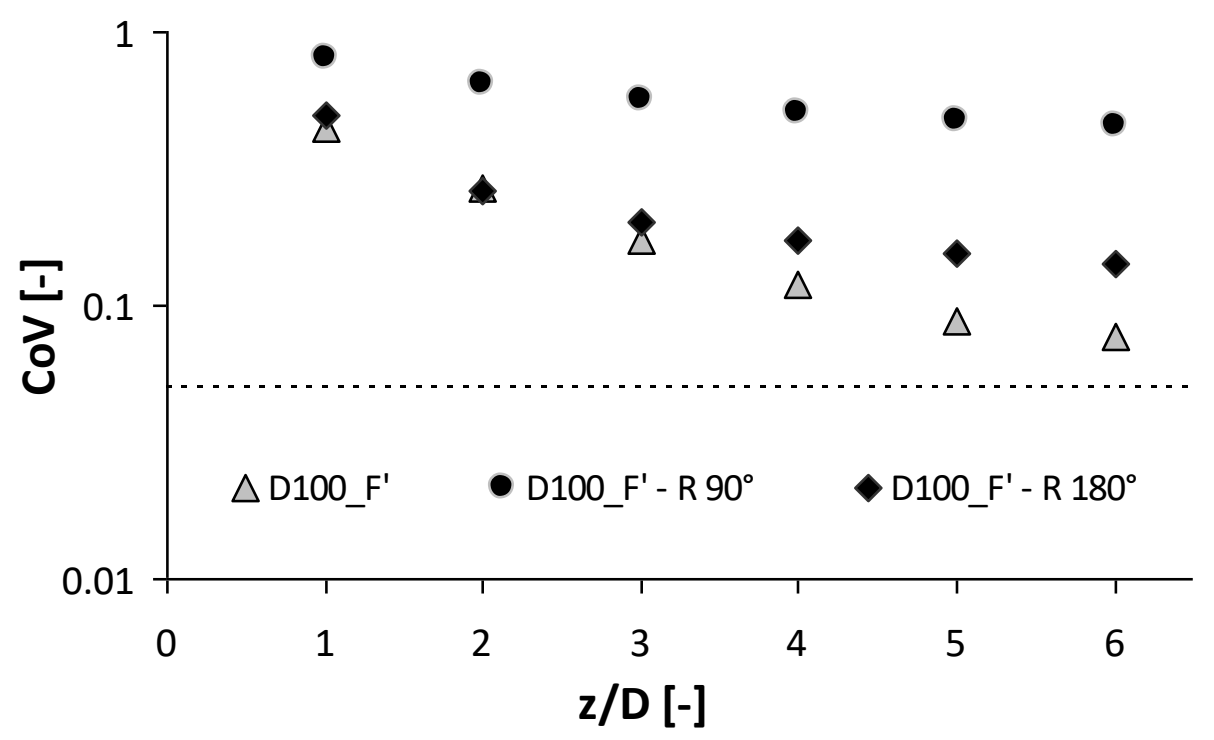

(a) 


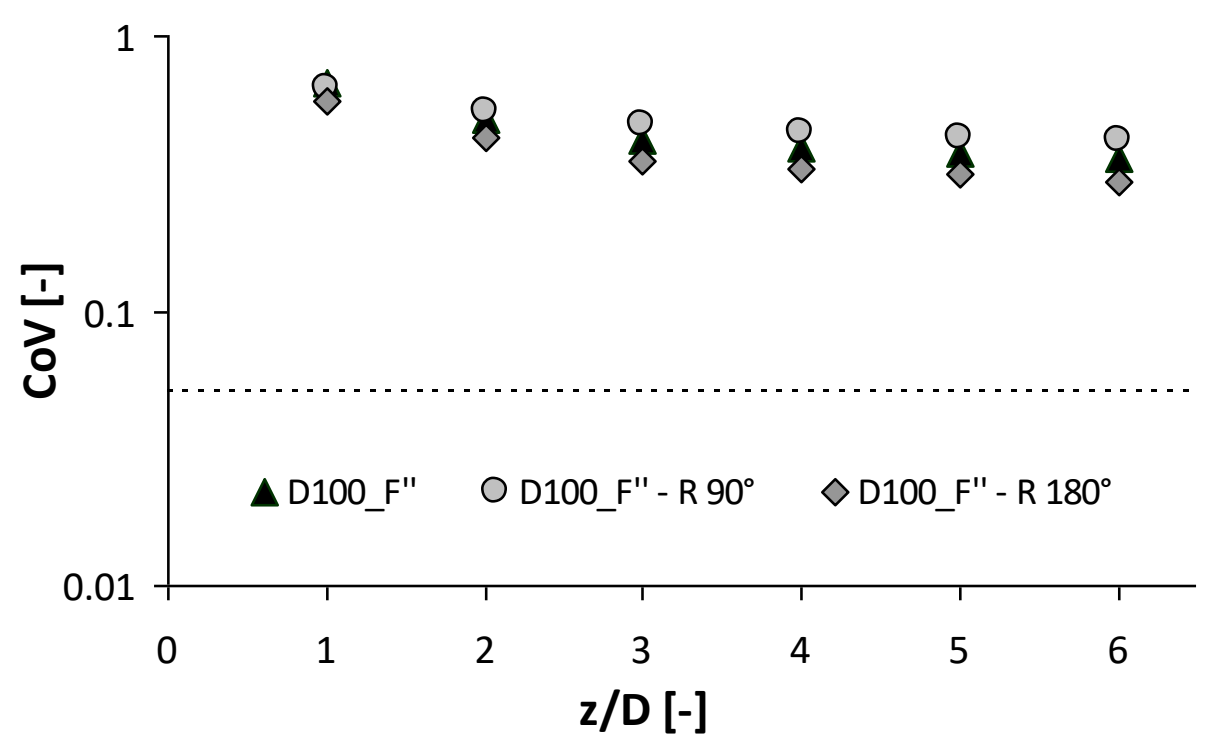

(b)

Fig. 10. Effect of the mixer orientation on the evolution of the CoV downstream of the mixer (a) D100_F'; (b) D100_F'.

In any case, the present results suggest to devote more attention to the combination of elements' orientation inside the tube and density difference, since an optimization of the arrangements can well lead to a reduction of the pipe length for the achievement of the same degree of homogeneity. 


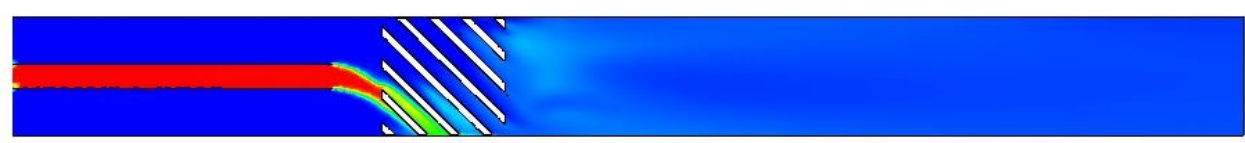

$\left(\mathrm{F}^{\prime}\right)$
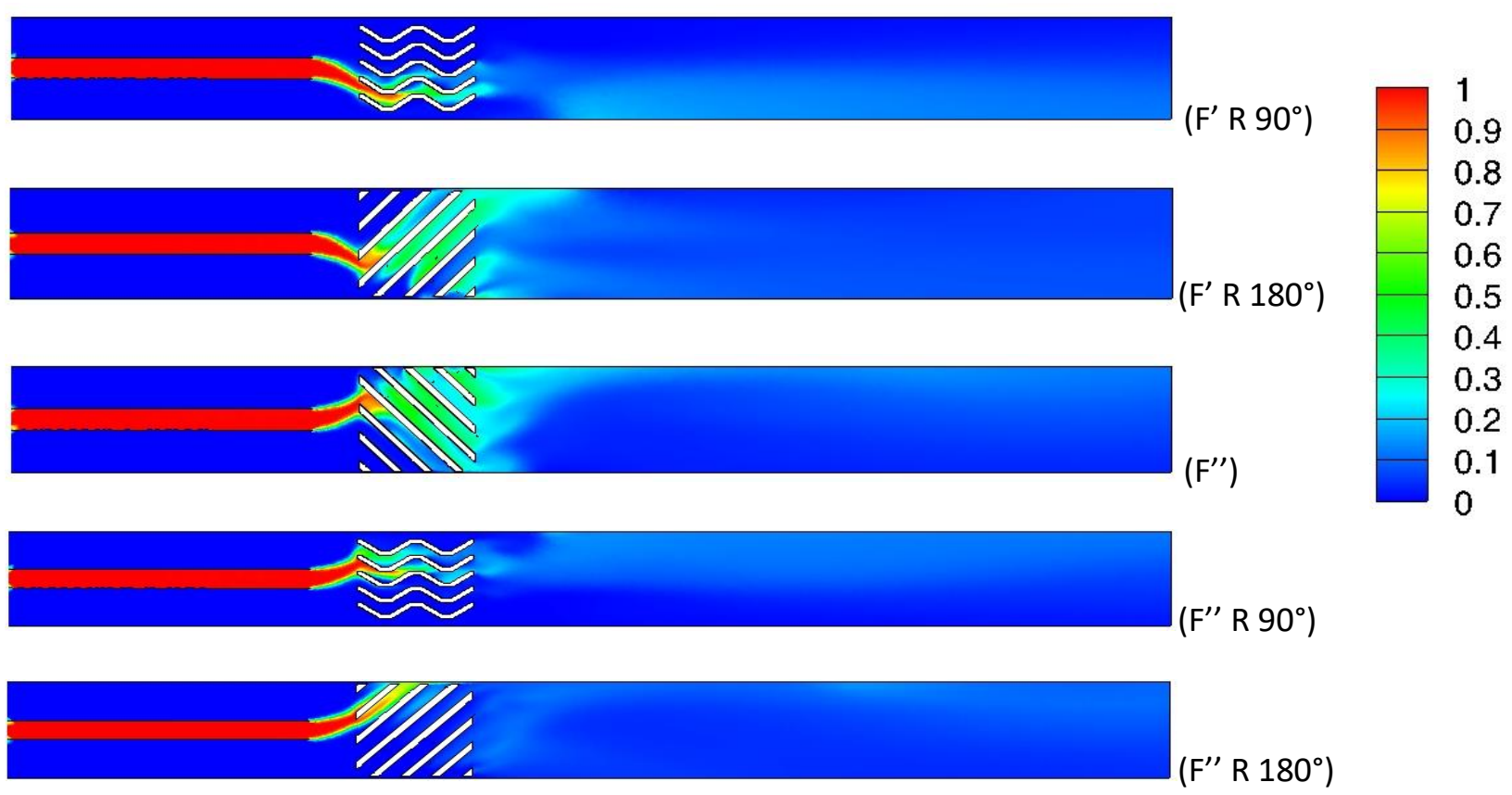

Fig. 11. Mass fraction of the secondary liquid for different element orientations on a vertical diametrical plane.

\subsection{The effect of the viscosity ratio}

The increase of viscosity of the main stream only is considered in cases D100_G and D100_G'. In the former case, the viscosity ratio, $\mu_{\mathrm{M}} / \mu_{\mathrm{S}}$, is equal to $6 / 1$ and in the latter to $15 / 1$, while the density difference is in both cases equal to that of case D100_F'. As a result of the modified flow rates adopted for maintaining the same Reynolds numbers, the Richardson number is much lower than in case F'. The CoV profiles shown in Fig. 12, together with those of cases F and F' for comparison, confirm that the intensity of segregation scales with the Richardson number also in the case of variations of the viscosity ratio.

Apparently, the viscosity difference under the same turbulent conditions does not affect the result, as is also confirmed from the maps shown in Fig. 13. 


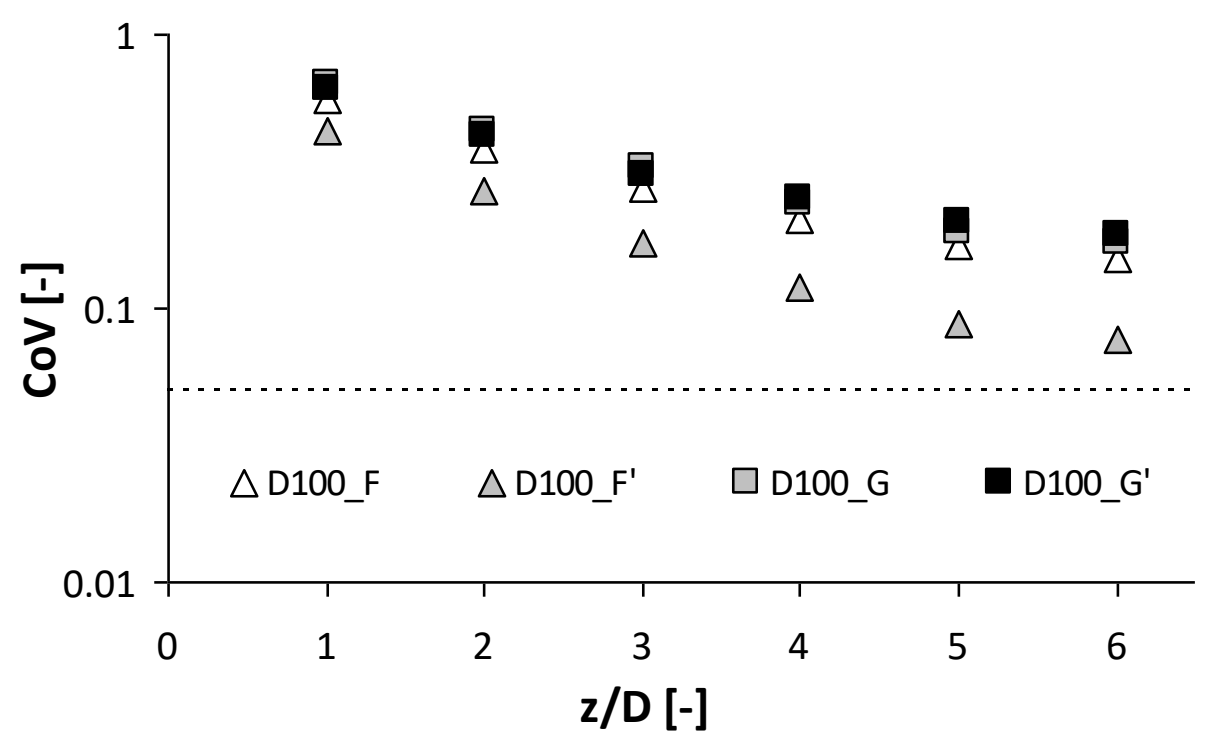

Fig. 12. CoV variation along the tube axis. Effect of the viscosity ratio (higher viscosity: main stream). (D100_F: Ri=0.0, $\mu_{\mathrm{M}} / \mu_{\mathrm{S}}=1$; D100_F': Ri=5.3, $\mu_{\mathrm{M}} / \mu_{\mathrm{S}}=1 ; \mathrm{D} 100 \_\mathrm{G}: \mathrm{Ri}=0.16, \mu_{\mathrm{M}} / \mu_{\mathrm{S}}=6$; D100_G': Ri=0.03, $\left.\mu_{\mathrm{M}} / \mu_{\mathrm{S}}=15\right)$.

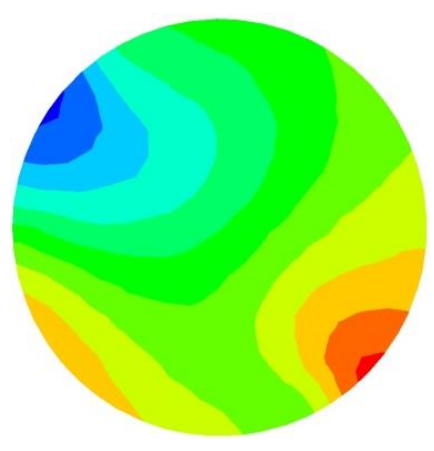

D100_G, $\mu_{\mathrm{M}} / \mu_{\mathrm{S}}=6$
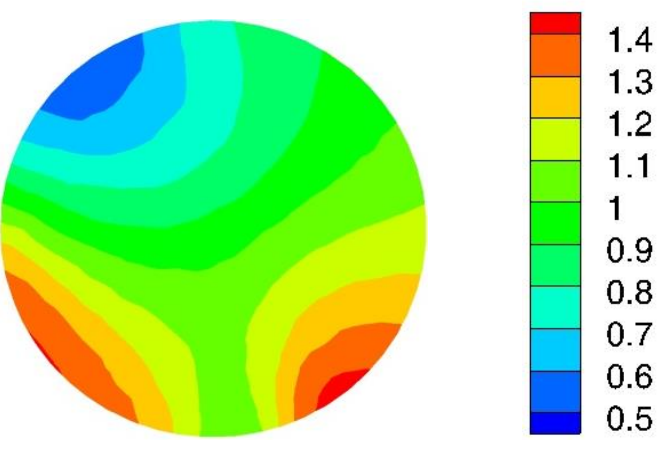

D100_G', $\mu_{\mathrm{M}} / \mu_{\mathrm{S}}=15$

Fig. 13. Normalized mass fraction of the secondary liquid at $\mathrm{z} / \mathrm{D}=5$. Effect of the viscosity ratio (higher viscosity: main stream).

For cases D100_H and D100_H', equal viscosity differences but reversed ratios were considered, that is $\mu_{\mathrm{M}} / \mu_{\mathrm{S}}$ of $1 / 6$ and of $1 / 15$, respectively. In order to maintain the same Reynolds number, a significant increase of the secondary flow rate has to be adopted. The corresponding $\mathrm{CoV}$ profiles and the normalized mass fractions of the secondary liquid on a cross section are shown in Figs. 14 and 15, respectively. As already observed for case D50_D, due to the back mixing upstream of the element, the modified flow rate ratio is the major responsible for the variation of the homogenization performances. In these cases, the liquid homogenization is not dominated by the Richardson number. 


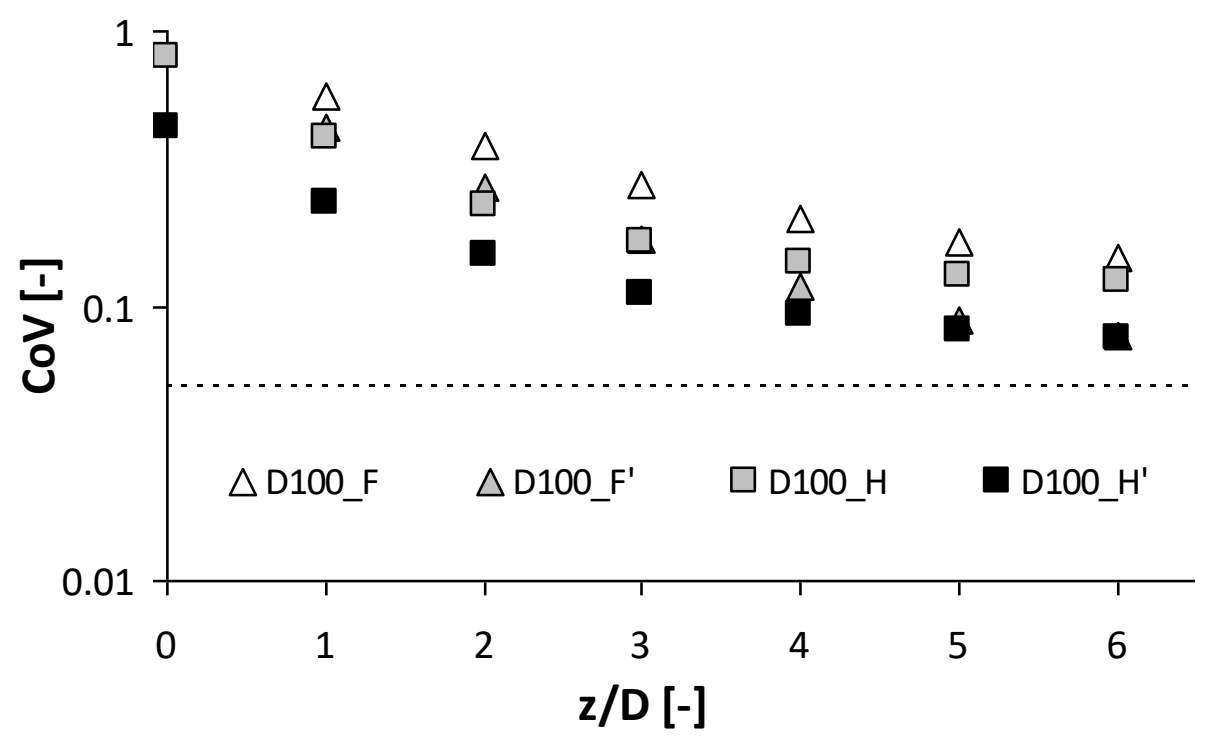

Fig. 14. CoV variation along the tube axis. Effect of the viscosity ratio (higher viscosity: secondary stream). (D100_F: $\mathrm{Ri}=0.0, \mu_{\mathrm{M}} / \mu_{\mathrm{S}}=1$; D100_F': $\mathrm{Ri}=5.3, \mu_{\mathrm{M}} / \mu_{\mathrm{S}}=1$; D100_H: Ri=3.21, $\mu_{\mathrm{M}} / \mu_{\mathrm{S}}=0.17$; D100_H': Ri=1.64, $\left.\mu_{\mathrm{M}} / \mu_{\mathrm{S}}=0.07\right)$.

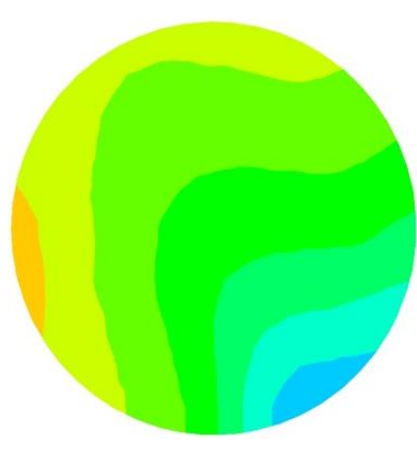

D100_H, $\mu_{\mathrm{M}} / \mu_{\mathrm{S}}=1 / 6$

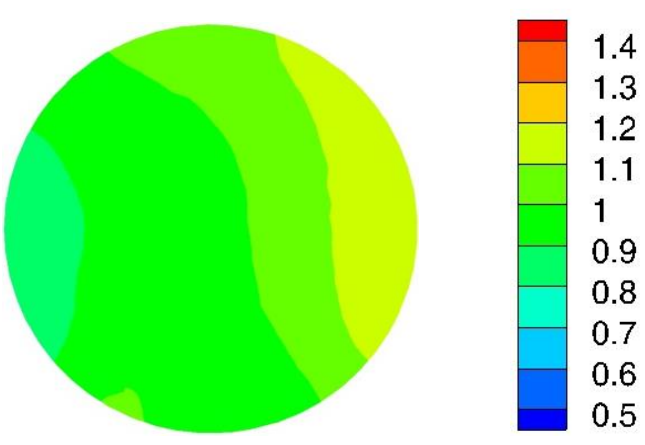

D100_H', $\mu_{\mathrm{M}} / \mu_{\mathrm{S}}=1 / 15$

Fig. 15. Normalized mass fraction of the secondary liquid at $\mathrm{z} / \mathrm{D}=5$. Effect of the viscosity ratio (higher viscosity: secondary stream).

\subsection{The dimensions of segregation}

In this section, the analysis of the results based on the concepts of intensity, scale and exposure of segregation is presented. Three cases are selected (namely, D100_F', D100_F', and D100_F' with the insert rotated of $180^{\circ}$ ), for which quite different $\mathrm{CoV}$ profiles were found, thus offering the possibility to test the usefulness of the parameters proposed for the estimation of the scale and exposure of segregation. In the following, computed area, $A_{M}$, length of the boundary zone, 
$\mathrm{L}_{\mathrm{M}}$, and equivalent diameter, $\mathrm{d}_{\mathrm{eq}}$, of the well mixed regions are given in dimensionless form, dividing for the area of the pipe cross section, the perimeter and the diameter of the pipe respectively.

In Fig. 16a, the total area of the well mixed cells at different cross sections is plotted as a function of the pipe length. The area and the $\mathrm{CoV}$ profiles lead to the same conclusions. $\bar{\gamma}$ It is in fact obvious that as the area of the well mixed zone increases, the intensity of the segregation decreases. Deeper insight into the physical reasons of different mixing performances, e.g. the crossing observed at $\mathrm{z} / \mathrm{D}=0.3$ with the two positions of the insert, or the absence of mixing improvements downstream of $\mathrm{z} / \mathrm{D}=3$ for $\mathrm{D} 100 \_\mathrm{F}$ ", cannot be obtained just considering the $\mathrm{CoV}$ or the well mixed area. For this reason the dimensionless perimeter and the equivalent diameter of the well mixed zone are plotted in Figs. 16b and 16c, respectively.

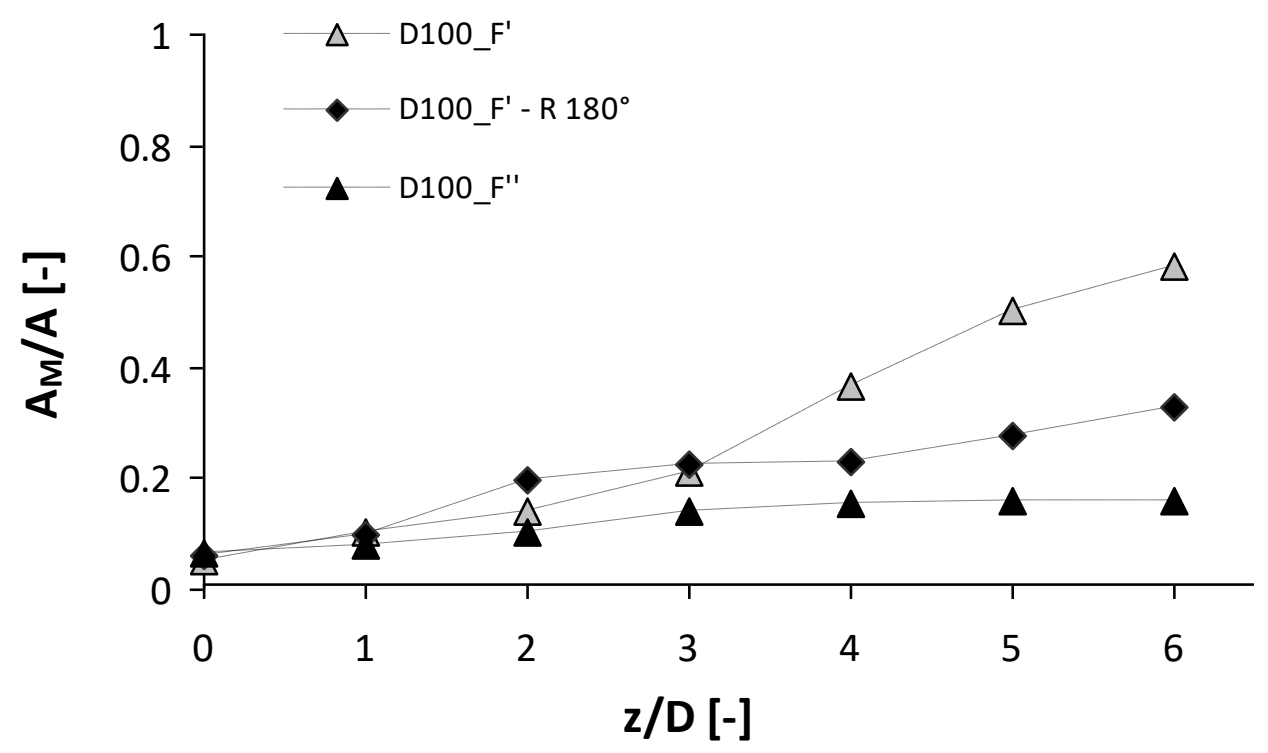

(a) 


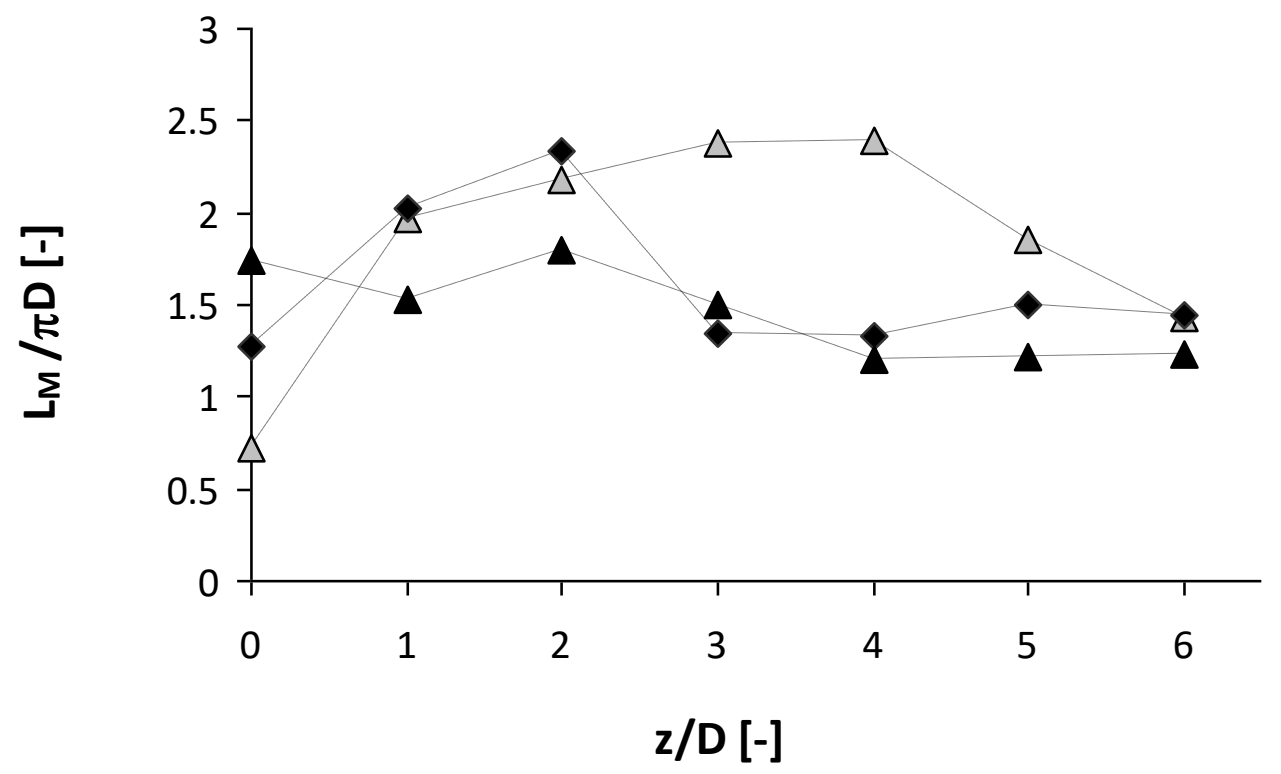

(b)

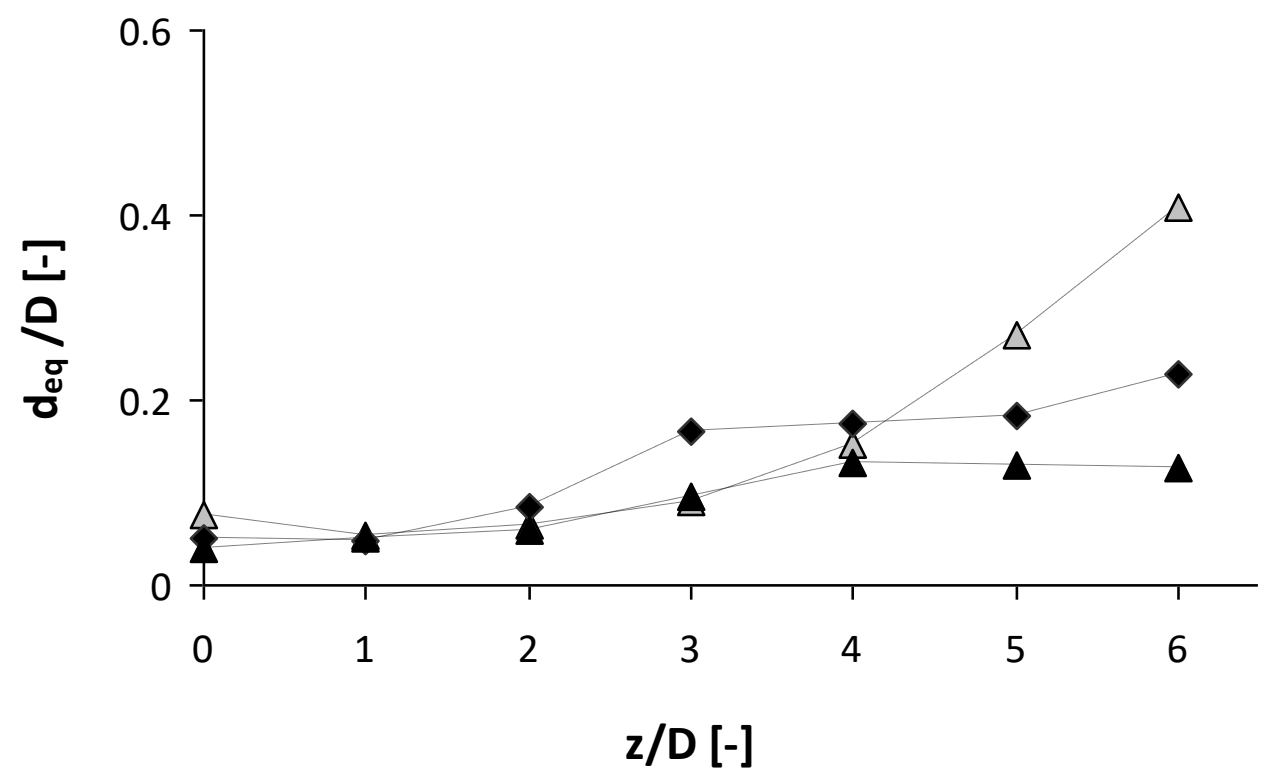

(c)

Fig. 16. Evolution of dimensionless $A_{M}(a), L_{M}(d)$ and $d_{e q}(c)$ downstream of the mixer for three different cases.

As for the comparison of the insert orientation, for $\mathrm{z} / \mathrm{D}<2$ the $180^{\circ}$ rotated insert gives a slightly greater $\mathrm{L}_{\mathrm{M}}$. Therefore, up to $2 \mathrm{D}$ downstream of the insert, a wider boundary is available for the exchange process, suggesting why the dimensionless size of the well mixed zone is slightly greater close to the insert. However, at $\mathrm{L} / \mathrm{D}=3$, a sharp reduction of $\mathrm{L}_{\mathrm{M}}$ is observed, that may well result into a reduction of the velocity of the mass transfer process with respect to the standard orientation. The combination of $\mathrm{A}_{M}$ and $\mathrm{L}_{\mathrm{M}}$ gives significantly different trends of the 
scale of the well mixed zone, $d_{\text {eq }}$, whose dimensionless values increase significantly moving far from the insert with the standard orientation, while very slight variations are observed for the rotated position after 3D from the mixer.

For D100_F', the dimensionless $\mathrm{L}_{\mathrm{M}}$ is generally smaller than that of the other two cases. From $\mathrm{L} / \mathrm{D}=4$ onwards, both the dimensionless $\mathrm{L}_{\mathrm{M}}$ and $\mathrm{d}_{\mathrm{eq}}$ do not show any significant variation, as a result, the mixing efficiency of the process becomes negligible.

Overall, the equivalent diameter allows grasping quantitatively the outcome of the complex interactions amongst the fluid dynamic variable on mixing and segregation. It can be adopted for a stricter and more fruitful evaluation of physical and geometrical variations with respect to the analysis of all the local variables calculated on the whole domain, which is often just based on visualization.

Additional useful information on the evolution of the mixing process along the pipe length is provided by the gradient of the equivalent diameter, shown in Figure 17.

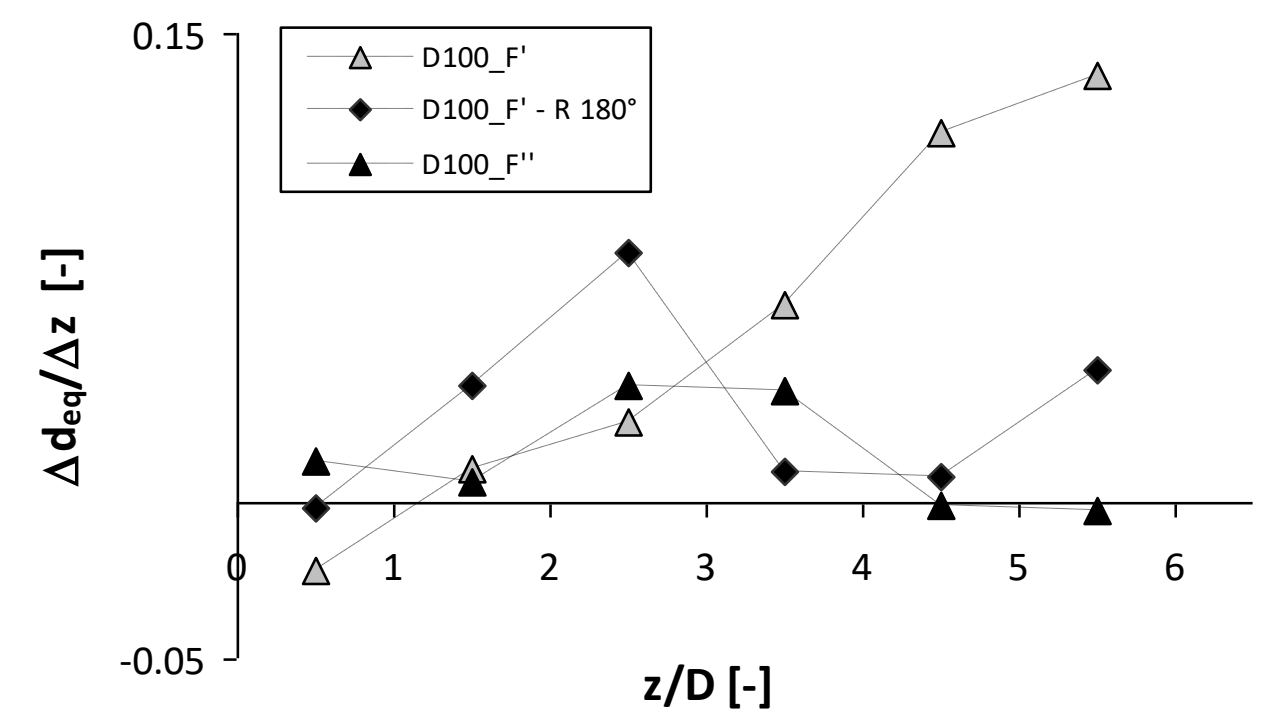

Fig. 17. Evolution of the $d_{\text {eq }}$ gradient downstream of the mixer for three different cases.

The value at $\mathrm{z} / \mathrm{D}=0.5$ is affected by the step change of conditions close to the insert. Elsewhere, the positive values of the rate of change of the equivalent diameter upstream of $z / D=3$ suggests that the mixing process gives rise to a reduction of the intensity of segregation, although to a different extent in the three cases. Upstream of $\mathrm{z} / \mathrm{D}=3$, the faster process occurs with the $180^{\circ}$ rotated insert, while from 3D downstream of the insert onwards, the gradient of $\mathrm{d}_{\text {eq }}$ approaches small values for the $\mathrm{F}^{\prime}{ }_{-} \mathrm{R} 180^{\circ}$ while is about nil for case $\mathrm{F}^{\prime}$. In this last case, despite the 
availability of surface area for mass transfer (Fig. 16b), improvements on mixing are not feasible just by providing additional pipe length, since the rate of change of segregation is nil. As a result different arrangements of the geometrical or physical variables are required.

Clearly, the slow or absent variation of the intensity of segregation already observed downstream of $\mathrm{z} / \mathrm{D}=3$ is strictly related to and can be better interpreted by the evaluation of the scale and the exposure of segregation. These two parameters are able to summarize the liquids mixing features, whose variations are expected to be mainly determined by the specific turbulent diffusivity field obtained under different conditions. In order to assess the relationship between the equivalent diameter and the turbulent diffusivity, the turbulent viscosity maps on one vertical section for the three cases are reported in Fig. 18. It is worth observing that the nil value of the $\mathrm{d}_{\text {eq }}$ gradient obtained for $\mathrm{z} / \mathrm{D}>5$ for D100_F', (Fig. 17) is consistent with the value of $\mu_{\mathrm{t}}$ reported in Fig. 18, that is much lower than that obtained in the same zone in the other two cases. As a result, the maps of the turbulent viscosity reported in Fig. 18 clarify the reason of the different values of $\mathrm{d}_{\mathrm{eq}}$ in the different cases.
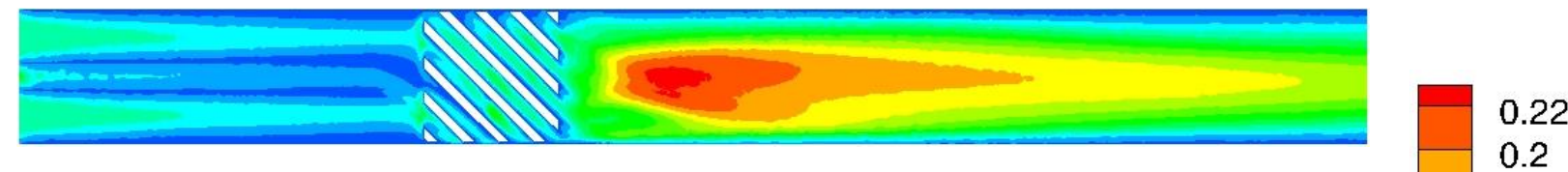

D100_F'
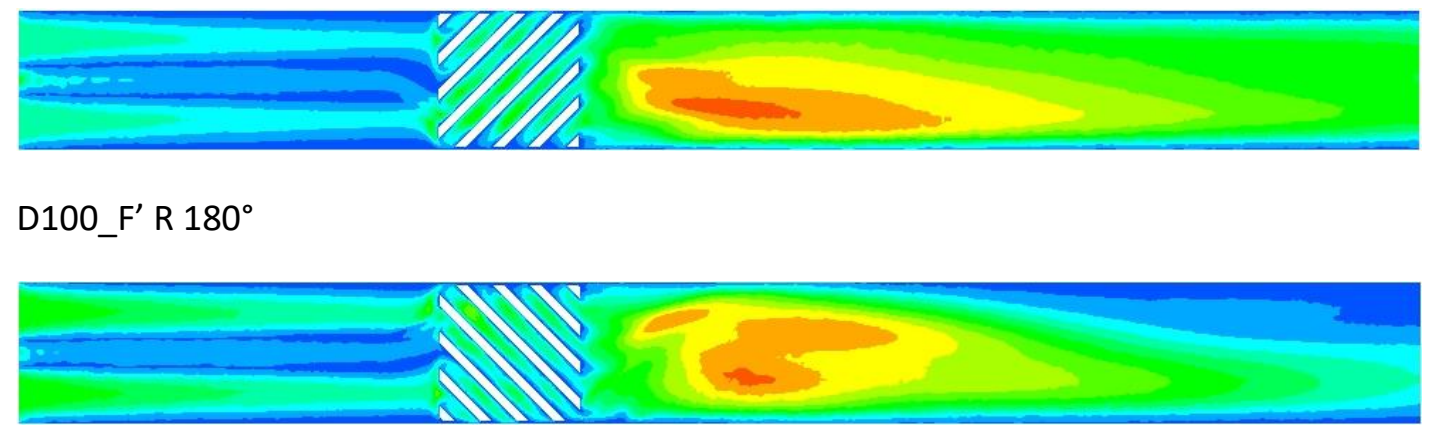

D100_F"

Fig. 18. Turbulent viscosity on a vertical diametrical plane for the three cases (color scale in $\mathrm{Pa} \cdot \mathrm{s})$.

Finally, based on the test cases discussed above, the characteristic size of the boundary zone between mixed and poorly mixed zones, the equivalent diameter and its gradient along the pipe axis allow to identify the outcome of the complex interactions amongst the controlling fluid 
dynamic variables: velocity, turbulent kinetic energy and its dissipation, which are responsible for mixing on the liquids blending.

\section{Conclusions}

The CFD analysis of the turbulent liquid blending of miscible liquids with static mixers has led to conclude that the density differences may give rise to significant variations of mixedness, depending on the Richardson number. As a result, the same density difference leads to different homogenization conditions depending on the equipment dimension. Also, the insert orientation inside the pipeline affects the total length for the achievement of the desired level of mixedness, depending on the physical properties of the two fluids. As for the viscosity differences, the analysis at constant Reynolds number does not allow to isolate the viscosity effect. Indeed, the flow rate variations required to achieve the same flow regime give rise to important back-mixing effects.

Besides the measurement of the intensity of segregation classically performed by the $\mathrm{CoV}$ calculation, the application of the concepts proposed by Kukukova et al. (2009) has led to the definition of the scale of segregation and of the exposure. These are additional and effective parameters to fully exploit the fluid dynamic variables obtained by the CFD simulations on the whole computational domain also in the case of turbulent blending considered in this works. They can be adopted as a more successful method for the mixedness evaluation than the simple $\mathrm{CoV}$ estimation. The investigation is carried on a simple geometry, including a single SMV element. The computational method and the parameters adopted for the analysis of the results can be easily extended to any combination of mixing elements, distributor geometry, pipeline scale. They can contribute to the identification of the best combination of geometrical arrangement and physical variables for improving the performances of turbulent static mixers.

\section{Notation}

$\mathrm{A}_{\mathrm{M}}$

$\mathrm{CoV}$

$\mathrm{D}$

$\mathrm{d}_{\mathrm{eq}}$

$\mathrm{D}_{\mathrm{m}}$

g

$\mathrm{k}$

L well mixed area, $\mathrm{m}^{2}$ coefficient of variation defined in Eqn. (11), dimensionless

pipeline diameter, $\mathrm{m}$

equivalent diameter, $\mathrm{m}$

molecular diffusivity, $\mathrm{m}^{2} \mathrm{~s}^{-1}$

gravity acceleration, $\mathrm{m} \mathrm{s}^{-2}$

turbulent kinetic energy, $\mathrm{m}^{2} \mathrm{~s}^{-2}$

pipe length, $\mathrm{m}$ 


$\begin{array}{ll}\mathrm{L}_{\mathrm{M}} & \begin{array}{l}\text { length of the boundary between well and poorly mixed zones, } \mathrm{m} \\ \mathrm{N}\end{array} \\ \mathrm{p} & \text { number of evaluation positions, dimensionless } \\ \mathrm{Q} & \text { flow rate, } \mathrm{m}^{3} / \mathrm{s} \\ \mathrm{r} & \text { radial coordinate, } \mathrm{mm} \\ \mathrm{Re} & \text { Reynolds number, dimensionless } \\ \mathrm{Ri} & \text { Richardson number, dimensionless } \\ \mathbf{U} & \text { mean velocity vector, } \mathrm{m} \mathrm{s}^{-1} \\ \mathrm{Y}_{\mathrm{i}} & \text { mass fraction of the species i, dimensionless } \\ \mathrm{Z} & \text { axial coordinate, } \mathrm{mm}\end{array}$

\section{Greek letters}

$\Phi_{\mathrm{i}}$

volumetric fraction of the species $i$, dimensionless

$\varepsilon$

turbulent dissipation, $\mathrm{m}^{2} \mathrm{~s}^{-3}$

$\mu \quad$ viscosity, $\mathrm{kg} \mathrm{m}-1 \mathrm{~s}^{-1}$

$\mu_{\mathrm{t}} \quad$ turbulent viscosity, $\mathrm{Pa} \mathrm{s}$

$\rho$

density, $\mathrm{kg} \mathrm{m}^{-3}$

$\sigma_{\mathrm{t}}$

turbulent Schmidt number, dimensionless

\section{References}

Alberini, F., Simmons, M.J.H., Ingram, A., Stitt, E.H. Assessment of different methods of analysis to characterise the mixing of shear-thinning fluids in a Kenics KM static mixer using PLIF. Chemical Engineering Science, 112, 152-169, 2014a.

Alberini, F., Simmons, M.J.H., Ingram, A., Stitt, E.H. Use of an areal distribution of mixing intensity to describe blending of non-newtonian fluids in a kenics $\mathrm{KM}$ static mixer using PLIF. AIChE Journal, 60, 332-342, 2014b.

Bałdyga, J., Bourne, J.R., Hearn, S.J. Interaction between chemical reactions and mixing on various scales. Chemical Engineering Science, 52, 457-466, 1997.

Bouwmans, I., Barker, A., Van Den Akker, H.E.A. Blending liquids of differing viscosities and densities in stirred vessels. Chemical Engineering Research and Design, 75, 777-783, 1997.

Brechtelsbauer, C., Ricard, F. Reaction engineering evaluation and utilization of static mixer technology for the synthesis of pharmaceuticals. Organic Process Research and Development, 5 (6), pp. 646-651, 2001. 
Brown D.R., Jones P.N., Middleton J.C., Papadopoulos G., Arik E.B., Chapter 4, Experimental methods, p. 272-273 , [in:] Paul, E.L., Atiemo-Obeng, V.A., Kresta, S.M. (Eds.), Handbook of Industrial Mixing, Wiley-Interscience: Hoboken, NJ.

Coroneo, M., Montante, G., Paglianti, A. Computational fluid dynamics modeling of corrugated static mixers for turbulent applications, Industrial and Engineering Chemistry Research, 51, 15986-15996, 2012.

Danckwerts, P. V., 1952, The Definition and Measurement of Some Characteristics of Mixtures, Appl Sci Res A, 3, 279-296.

Derksen, J.J. Blending of miscible liquids with different densities starting from a stratified state. Computers and Fluids, 50, 35-45, 2011.

Derksen, J.J. Direct simulations of mixing of liquids with density and viscosity differences. Industrial and Engineering Chemistry Research, 51, 6948-6957, 2012.

Etchells A. W., Meyer C. F., 2004. Chaper 7, Mixing in Pipelines, pp. 422-424, p. 460, [in:] Paul, E.L., Atiemo-Obeng, V.A., Kresta, S.M. (Eds.), Handbook of Industrial Mixing, Wiley-Interscience: Hoboken, NJ.

Feng, H., Olsen, M.G., Hill, J.C., Fox, R.O., Simultaneous velocity and concentration field measurements of passive-scalar mixing in a confined rectangular jet. Experiments in Fluids, 42, 847-862, 2007.

Feng, H., Olsen, M.G., Hill, J.C., Fox, R.O. Investigation of passive scalar mixing in a confined rectangular wake using simultaneous PIV and PLIF. Chemical Engineering Science, 65, 3372-3383, 2010.

Fonte C.P., Sultan M.A., Santos R.J., Dias M.M., Lopes J.C.B., Flow Imbalance and Reynolds Number Impact on Mixing in Confined Impinging Jets, Chemical Engineering Journal, 260, 316-330, 2015.

Ghanem, A., Lemenand, T., Della Valle, D., Peerhossaini, H. Static mixers: Mechanisms, applications, and characterization methods - A review. Chemical Engineering Research and Design, 92 (2), pp. 205-228, 2014.

Gogate, P.R., Pandit, A.B. Mixing of miscible liquids with density differences: Effect of volume and density of the tracer fluid. Canadian Journal of Chemical Engineering, 77, 988-996, 1999.

Habchi, C., Lemenand, T., Valle, D.D., Peerhossaini, H. Turbulent mixing and residence time distribution in novel multifunctional heat exchangers-reactors. Chemical Engineering and Processing: Process Intensification, 49, 1066-1075, 2010. 
Hartmann, H., Derksen, J. J., Van den Akker, H. E. A. Mixing times in a turbulent stirred tank by means of LES, AIChE Journal, 52, 3696-3706, 2006.

Jaworski, Z.; Pianko-Oprych, P.; Marchisio, D. L.; Nienow, A. W. CFD modelling of turbulent drop breakage in a Kenics static mixer and comparison with experimental data. Chem. Eng. Res. Des., 85, 753-759, 2007.

Jones, S.C., Sotiropoulos, F., Amirtharajah, A. Numerical modeling of helical static mixers for water treatment. Journal of Environmental Engineering, 128 (5), 431-440, 2002.

Karoui, A.; Le Sauze, N.; Costes, J.; Bertrand, J. Experimental and numerical study of flow at the outlet of Sulzer SMV static mixers, Récents Progrès en Génie des Procédés, 11, 323330, 1997.

Karoui, A.; Hakenholz, F.; Le Sauze, N.; Costes, J.; Bertrand, J. Determination of the mixing performance of sulzer SMV static mixers by laser induced fluorescence, Can. J. Chem. Eng., 76, 522-526, 1998.

Kukukova, A., Aubin, J., Kresta, S.M. A new definition of mixing and segregation: Three dimensions of a key process variable. Chemical Engineering Research and Design, 87 (4), pp. 633-647, 2009.

Kukukova, A., Aubin, J., Kresta, S.M. Measuring the scale of segregation in mixing data. Canadian Journal of Chemical Engineering, 89 (5), pp. 1122-1138, 2011.

Kumar, V., Shirke, V., Nigam, K.D.P. Performance of Kenics static mixer over a wide range of Reynolds number. Chemical Engineering Journal, 139 (2), pp. 284-295, 2008.

Launder, B.E.; Spalding, D.B. The numerical computation of turbulent flows, Comput. Meth. Appl. Mech. Engrg, 3, 269-289, 1974.

Marshall E.M, A. Bakker, 2004. Chapter 5, Computational Fluid Mixing, p. 325, [in:]in Paul, E.L., Atiemo-Obeng, V.A., Kresta, S.M. (Eds.), Handbook of Industrial Mixing, WileyInterscience: Hoboken, NJ.

Mohand Kaci, H., Lemenand, T., Della Valle, D., Peerhossaini, H. Effects of embedded streamwise vorticity on turbulent mixing. Chemical Engineering and Processing: Process Intensification, 48, 1459-1476, 2009.

Paglianti, A., Montante, G. A mechanistic model for pressure drops in corrugated plates static mixers, Chemical Engineering Science, 97, 376-384, 2013.

Rabha, S., Schubert, M., Grugel, F., Banowski, M., Hampel, U. Visualization and quantitative analysis of dispersive mixing by a helical static mixer in upward co-current gas-liquid flow. Chemical Engineering Journal, 262, pp. 527-540, 2015. 
Rakoczy, R., Masiuk, S., Kordas, M., Gradzik, P. The effects of power characteristics on the heat transfer process in various types of motionless mixing devices. Chemical Engineering and Processing: Process Intensification, 50 (9), pp. 959-969, 2011.

Regner, M., Östergren, K., Trägårdh, C. Influence of viscosity ratio on the mixing process in a static mixer: Numerical study. Industrial and Engineering Chemistry Research, 47, 30303036, 2008.

Rielly, C.D., Pandit, A.B. The mixing of Newtonian liquids with large density and viscosity differences in mechanically agitated contactors. Proceeding of the $6^{\text {th }}$ European Conference on Mixing. Pavia, Italy: 24-26 May, 1988, pp- 69-77.

Streiff, F., A., Jaffer, S., Schneider, G., 1999. The design and application of static mixer technology. Third International Symposium on Mixing in Industrial Processes. Osaka, Japan, September 19th-22th., 107-114.

Thakur, R., K., Vial, Ch., Nigam, K., D., P., Nauman, E., B., Djelveh, G.. Static Mixers in the process industries- A review, Chemical Engineering Research and Design, 81, 2003, 787 826.

Theron, F., Sauze, N.L. Comparison between three static mixers for emulsification in turbulent flow. International Journal of Multiphase Flow, 37, 488-500, 2011.

Ugwu, C.U., Ogbonna, J.C., Tanaka, H. Improvement of mass transfer characteristics and productivities of inclined tubular photobioreactors by installation of internal static mixers. Applied Microbiology and Biotechnology, 58, 600-607, 2002.

van Wageningen, W. F. C.; Kandhai, D.; Mudde, R. F.; van den Akker, H. E. A. Dynamic flow in a Kenics static mixer: an assessment of various CFD methods. AIChE J. 50, 1684-1696, 2004.

Zhao, L., Derksen, J., Gupta, R. Simulations of axial mixing of liquids in a long horizontal pipe for industrial applications. Energy and Fuels, 24, 5844-5850, 2010. 